\title{
Reputational Herding in Financial Markets: A Laboratory Experiment
}

\author{
Andreas Roider $^{\mathrm{a}}$ and Andrea Voskort ${ }^{\mathrm{b}}$ \\ ${ }^{a}$ University of Regensburg; ${ }^{b}$ Federal Financial Supervisory Authority (BaFin)
}

\section{ABSTRACT}

We study reputational herding in financial markets in a laboratory experiment. In the spirit of Dasgupta and Prat [2008], career concerns are introduced in a sequential asset market where wages for investors are set by subjects in the role of employers. Employers can observe investment behavior, but not investors' ability types. Thereby, reputational incentives may arise endogenously. We find that a sizable fraction of investors follows an established trend even in a setting where there are no reputational incentives. In a setting where there are reputational concerns, they do not seem to create substantial herd behavior.

\section{KEYWORDS}

Reputation; Herding; Imitation; Financial markets; Experiment

\section{Introduction}

They [equity investors] are not paid to make money, or even to beat the market. Rather, they are paid not to do worse than their peers. Going down with the market would not be so bad for them; missing out on a rally like in 2009, when stocks doubled in barely two years, would be catastrophic for their career. -Comment by J. Authers, "Dangers of Market Herd Stampedes," Financial Times, November 30, 2011

\section{Motivation}

The popular press frequently alludes to herd behavior as a potential source of mispricing in financial markets. Also, there is a substantial academic literature (both theoretical and empirical) on this phenomenon. Perhaps surprisingly, even when investors are purely profit-maximizing, herding might arise in financial markets, and market prices might fail to converge to true values even in the long run. One strand of the literature suggests that this might be due to "social learning" on part of individual investors (see, e.g., Park and Sabourian [2011], Avery and Zemsky [1998]). In particular, these authors introduce information cascade models (in the spirit of Bikhchandani, Hirshleifer and Welch [1992], Banerjee [1992], Welch [1992]) into a Glosten and Milgrom [1985] style sequential asset market, and they show that, despite a flexible market price, herd behavior might occur. ${ }^{1}$

As the above quotation suggests, another potential source of herd behavior is reputational concerns of individual investors (e.g., fund managers) vis-à-vis outside observers (e.g., potential future employers). In particular, Dasgupta and Prat [2008] introduce career concerns (in the spirit of
Scharfstein and Stein [1990]) in the Glosten and Milgrom [1985] model by assuming that investors are of various (unobservable) ability types. In analogy to Avery and Zemsky [1998], Dasgupta and Prat [2008] show that, following a number of trades in the same direction, the profit from trading an asset becomes smaller because prices get more precise. At the same time, if one's private information runs counter to the behavior of earlier investors, acting on the own signal implies a reputational loss, which might make it optimal to herd. Intuitively, if several predecessors have bought the same asset, with high probability a trade contrarian to predecessors' decisions and according to the own signal would turn out to be unsuccessful. As a consequence, the respective investor would incur a reputational loss as he or she would be considered as a low-ability investor. Hence, it might be optimal to neglect one's own information and to herd on predecessors' decisions in order not to harm one's reputation. From that moment onwards, prices remain constant and all subsequent investors follow the crowd. ${ }^{2}$

Of course, beyond social-learning or reputation-based explanations, there might still be other reasons for herd behavior. For example, herding might also be driven by investors following their "animal spirits" as Akerlof and Shiller [2008, p. 1] have put it. ${ }^{3}$

\section{Experimental setup}

In the present paper, we turn to the laboratory to study whether Dasgupta and Prat's [2008] theory of reputational herding can explain financial market behavior. Their theory suggests that investors engage in herd behavior if they face reputational incentives and asset 
prices get sufficiently precise (i.e., profits from trading get sufficiently small). ${ }^{4}$

In the experiment, subjects in the role of financial investors make the decision of which of two assets to buy. Subjects' investment behavior in two treatments is studied via the strategy method. While in a treatment investment subjects make their decisions in the absence of career concerns, in a treatment reputation career concerns are incorporated endogenously. For their investment choice, investors observe investment decisions of predecessors and a signal about which asset is the successful one. Investors can be of two types. Each investor is either a good type (and receives an informative signal about the assets' value), or a bad type (and receives an uninformative signal). Subjects are not aware of their type.

In treatment investment, the investor's profit consists of the final payoff of the asset bought minus the price paid for it. In this setup, according to theory, investors should always follow their own signal and buy the respective asset. That is, there should be sincere trading only. Treatment reputation additionally introduces principals who set wages for each investor based on the observed investment choices and the actual outcome of the asset. Investors thus receive wages set by the principals on top of earning profits from investing in the asset. In treatment reputation, investors should engage in herd behavior and neglect their own signal if a sufficient number of predecessors bought the same asset.

In the experiment, we introduce explicit wage setting by principals (as opposed to simply paying investors a wage equal to their conditional expected productivity) because whether reputational herding indeed emerges might, in principle, depend on two factors: namely, on whether investors recognize reputational incentives and whether an outside labor market indeed provides such incentives.

\section{Main insights}

The experimental results show that, as suggested by Dasgupta and Prat [2008], herd behavior can be observed in treatment reputation. About half of the investors engage in herding in the situations where it is predicted by theory. Again, as suggested by theory, in all other situations almost all subjects trade sincerely. However, surprisingly, even in treatment investment, herd behavior occurs to a similar extent. Hence, a substantial fraction of investors seems to follow an established trend even in the absence of reputational incentives, and reputational concerns do not seem to affect behavior much.

The findings of the experiment contribute to our understanding of to which degree reputational herding affects financial markets. One mechanism of how reputational concerns might influence investment behavior has been suggested by Dasgupta and Prat [2008]. Our results suggest that this mechanism is not at work in financial markets and, hence, does not distort asset prices. Thereby, our results complement empirical studies on financial markets (to be discussed below), which also document only limited evidence for reputational herding. ${ }^{5}$ If the widespread presumption that herd behavior is present in financial markets is true, such herd behavior might lead to substantial mispricing of assets and misallocation of capital. Our results hint that such herd behavior is not driven by reputational concerns, but other (behavioral) forces might be at work (as suggested by the imitation we observe in the experiment). To better understand these forces, more research is warranted. Understanding the exact reasons for herd behavior is important in order to potentially come up with ways of how to reduce this source of mispricing in financial markets.

\section{Outline}

The remainder of the paper is structured as follows. The related literature is discussed in the second section. In the third section, we introduce Dasgupta and Prat's [2008] model and present the theoretical benchmarks. In the fourth section, we outline the experimental design. The experiment's results are discussed in the fifth section followed by concluding remarks in the sixth section. In addition, we provide details with respect to the derivation of the theoretical benchmarks (Appendix A), an English translation of the experimental instructions (Appendix B), and an example of how individual payoffs were calculated in the experiment (Appendix C).

\section{Related literature}

The present paper contributes to three strands of the literature.

\section{Empirical literature on herd behavior in financial markets}

There is a substantial empirical literature on herd behavior in financial markets (for surveys, see, e.g., Bikhchandani and Sharma [2000], Daniel, Hirshleifer and Teoh [2002], or Hirshleifer and Teoh [2003]). This literature has two aims: to verify whether there is herding in financial markets, and, if yes, to investigate the reasons for herd behavior. In particular, various authors have investigated whether, due to career concerns, there is reputational herding by investment newsletters (see, e.g., Graham [1999]), macroeconomic forecasters (see, e.g., Lamont [2002], Ehrbeck and Waldmann [1996]), security analysts (see, e.g., Hong and Kubik [2003], Hong, Kubik and Solomon [2000], Welch [2000]), mutual fund managers (see, e.g., Massa and Patgiri [2007], 
Chevalier and Ellison [1999]), or institutional investors (see, e.g., Sias [2004]). In summary, these papers only provide mixed evidence for the presence of reputational herding in financial markets. For example, Sias [2004] and Ehrbeck and Waldmann [1996] fail to find evidence for reputationdriven herd behavior. Welch [2000] argues that the observed clustering of behavior could be due to either social learning or due to reputational concerns of investors.

This empirical literature has, however, a potential shortcoming. Frequently, neither the private information on which financial market participants act nor the performance incentives or reputational incentives they face are observable to the econometrician. Consequently, Hirshleifer and Teoh [2003] argue that, for an empirical study, it will always be difficult to disentangle to which degree reputational concerns, social learning, or simple imitation contribute to herd behavior in financial markets. Hence, we make the following contributions to this literature. From a methodological perspective, by conducting an experiment, we are able to control for the private information and monetary incentives faced by the decision makers, thereby circumventing the problems of empirical studies to observe these key variables. ${ }^{6}$ Our results complement and confirm the mixed findings of the empirical literature: we document that also under the controlled conditions of a laboratory experiment herding due to reputational reasons seems to be rather weak. Our experiment also shows that other (behavioral) forces seem to lead financial market participants to follow established trends, thereby emphasizing the need to study behavioral explanations for herd behavior in financial markets.

\section{Experimental literature on herd behavior in financial markets}

There is also a recent experimental literature on herd behavior in financial markets. These papers have not studied reputational herding, but they have mainly focused on settings where herding might be caused by "social learning" (i.e., where any herding is "purely information-based"). That is, they consider settings where the decisions of early investors might potentially reveal so much information about an asset's value such that, for later investors, it becomes optimal to disregard their own private information and to follow an established herd instead. ${ }^{7}$ These studies document that, under certain conditions, social learning indeed leads experimental subjects to engage in herd behavior, thereby lending support to social learning as a source of herding in financial markets. For example, Park and Sgroi [2010] lend support to Park and Sabourian [2011], whose model predicts that there might be information-based herding in settings that are sufficiently complex (i.e., where there are more than two possible states of the world). ${ }^{8}$ We contribute to this experimental literature by studying to which degree reputational concerns lead to herd behavior. In contrast to this literature, from a theoretical perspective, social learning does not play a role in the settings we consider. Our results provide experimental evidence that reputational forces might be of minor importance for the emergence of herd behavior in financial markets. Instead, we find that investors tend to follow an established trend even when there are no reputational incentives. Such simple imitation has rarely been observed in the earlier experiments; highlighting that it might be of greater importance than previously thought.

\section{Experimental literature on career concerns}

Our paper is also related to the experimental literature on career concerns. This literature has mostly focused on reputational concerns in labor markets. For example, Koch, Morgenstern and Raab [2009] experimentally test Holmstrom's [1999] seminal career concerns model. In this model, through providing effort, an agent tries to influence the beliefs of potential employers about their unknown ability, which has an impact on their future wages. Koch, Morgenstern and Raab [2009] find that, in line with the theoretical prediction, reputational concerns indeed shape the agent's behavior. ${ }^{9}$ We contribute to this literature by studying career concerns not in a labor market context, but in a financial market. In this setting, we find only weak evidence for the impact of reputational concerns.

\section{Theoretical benchmark}

\section{Basic structure}

We consider a simplified version of Dasgupta and Prat [2008] to make it suitable for a laboratory experiment. The sequence of events is illustrated in Figures 1 and 2. There are four dates $t \in\{1,2,3,4\}$ and three risk-neutral, profit-maximizing investors $i \in\{1,2,3\} .{ }^{10}$ Investors have to decide sequentially which of two assets, $A$ or $B$, to buy, and at date $t=i$ it is investor $i$ 's turn to buy either one unit of Asset $A$ or one unit of Asset $B .{ }^{11}$

Only one of the assets will turn out to have a value of 10 points (our experimental currency) at date $t=4$, while the other asset will have a value of 0 points. Both states $v \in\{A, B\}$ (i.e., which asset has a value of 10 points) occur with equal probability, and this is known to investors. The state of the world is the same for all three investors. As additional information, each investor receives a 


\begin{tabular}{|c|c|c|c|c|}
\hline & $\mathrm{t}=1$ & $\mathrm{t}=2$ & $\mathrm{t}=3$ & $\mathrm{t}=4$ \\
\hline \multirow[t]{2}{*}{$\begin{array}{l}V \text { and type of } \\
\text { each investor } \\
\text { determined, } \\
\text { not revealed }\end{array}$} & $\begin{array}{c}\text { Investor } 1 \\
\text { enters market } \\
\text { and receives } \\
\text { private signal }\end{array}$ & $\begin{array}{l}\text { Investor } 2 \text { enters } \\
\text { market, receives } \\
\text { private signal and } \\
\text { observes decision } \\
\text { of Investor } 1\end{array}$ & $\begin{array}{l}\text { Investor } 3 \text { enters } \\
\text { market, receives } \\
\text { private signal and } \\
\text { observes decisions } \\
\text { of Investor } 1 \text { and } 2\end{array}$ & $\begin{array}{c}v \text { revealed, } \\
\text { payoffs realized }\end{array}$ \\
\hline & $\begin{array}{l}\text { Investor } 1 \\
\text { buys Asset A } \\
\text { or B, pays } \\
\text { price of asset } \\
\text { bought }\end{array}$ & $\begin{array}{l}\text { Investor } 2 \\
\text { buys Asset A } \\
\text { or B, pays } \\
\text { price of asset } \\
\text { bought }\end{array}$ & $\begin{array}{l}\text { Investor } 3 \\
\text { buys Asset A } \\
\text { or B, pays } \\
\text { price of asset } \\
\text { bought }\end{array}$ & \\
\hline
\end{tabular}

Figure 1. Sequence of Events without Reputational Concerns.

private signal $s^{i} \in\{a, b\}$. The signal's precision depends on the respective investor's type, where each investor has an equal probability of being either "good" or "bad." In the case of a good investor, we have $\sigma_{g}=\operatorname{Prob}\left(s^{i}=a \mid v\right.$ $=A)=\operatorname{Prob}\left(s^{i}=b \mid v=B\right)=0.9$, while in the case of a bad investor we have $\sigma_{b}=\operatorname{Prob}\left(s^{i}=a \mid v=A\right)=\operatorname{Prob}\left(s^{i}\right.$ $=b \mid v=B)=0.5$. For each investor, the signal is drawn independently conditional on the state and the investor's type. That is, while a good investor receives additional information by observing the signal, a bad investor's signal is uninformative. Denote the asset bought by investor $i$ by $V^{i} \in\{A, B\}{ }^{12}$ The state of the world as well as the investors' types are determined at the beginning of the game. Investors do not learn their type throughout the game, and the state of the world (and, hence, investors' payoffs) is only revealed after all investment decisions have been made. ${ }^{13}$ When making their investment decision, each investor can rely on three pieces of information: (a) their privately observed signal, (b) the current market prices for Assets $A$ and $B$, and (c) the investment decisions of earlier investors (if there are any) as well as the history of market prices these earlier investors have faced. How market prices for the assets are determined is explained in more detail below.

\section{No reputational concerns of investors}

In a first step, we consider a benchmark setting where the investors do not have reputational concerns because they only derive a profit from buying one of the assets. Market prices are set by a risk-neutral, competitive market maker who efficiently incorporates all publicly available information, that is, the history of trades as well as the investor's decision to buy the respective asset. Hence, the market price of Asset $A$ at time $t$ is given by

$$
p_{A}^{t}=10 \cdot \operatorname{Prob}\left(A \mid H^{t}, \text { buy } A\right),
$$

and the price of Asset $B$ is equal to $p^{t}{ }_{B}=10 \cdot \operatorname{Prob}\left(B \mid H^{t}\right.$, buy $B$ ), where $H^{t}$ denotes the history of observable decisions of all earlier investors up to time $t$. Other experiments (such as Drehmann, Oechssler and Roider [2005], Cipriani and Guarino [2005]) have assumed that the market maker does not condition the prices $p_{A}^{t}$ and $p_{B}^{t}$ on the kind of order he or she receives at time $t$ (and, hence, is not fully profit-maximizing). We deviate from this and assume the price-setting rule (1) because it facilitates more "extreme" prices earlier on in a given sequence of investors. ${ }^{14}$ In the current benchmark

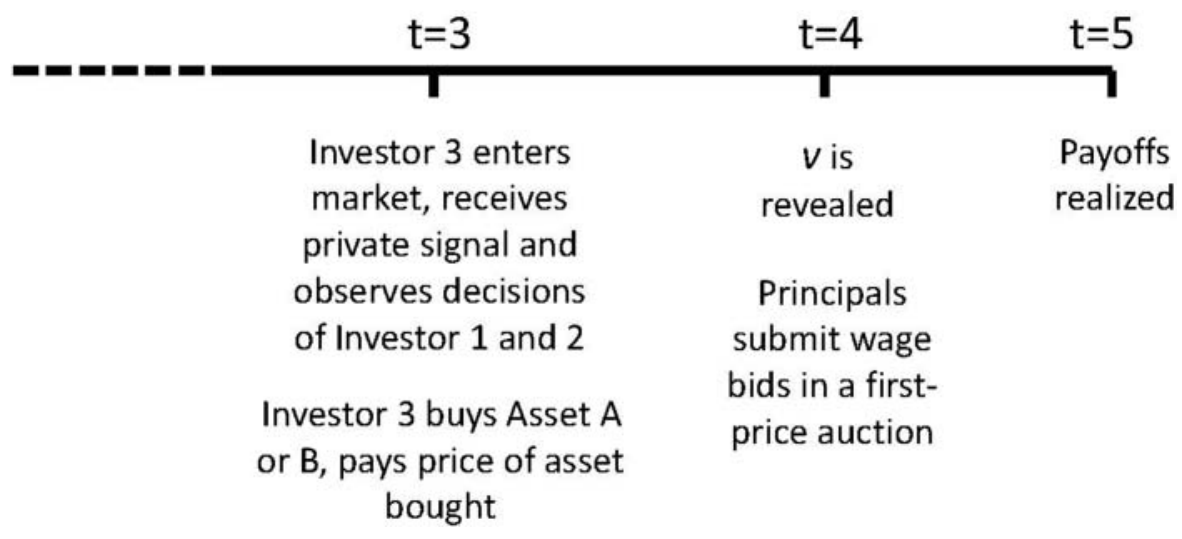

Figure 2. Sequence of Events with Reputational Concerns. 
setting, the overall payoff of investor $i$ is given by

$$
\pi_{I}^{i}\left(V^{i}, p_{V^{i}}^{t}, v\right) \equiv \begin{cases}10-p_{V^{i}}^{t} & \text { if } V^{i}=v \\ -p_{V^{i}}^{t} & \text { if } V^{i} \neq v\end{cases}
$$

for $i=t \in\{1,2,3\}$ (because investor $i$ buys at time $t=i$ only).

In line with earlier results by Glosten and Milgrom [1985] and Avery and Zemsky [1998], if investors are only motivated by profits from trading, all trading will be sincere (i.e., all investors will act according to their signal). Hence, investors reveal their private signal through their investment decision to the market maker. To see this, suppose that the market maker believes that trading has been sincere and suppose that investor $i$ has received signal $s^{i}=a$. In this case, the price of $A$ will equal the investor's expected value of $A$, and hence buying $A$ yields the investor an expected profit of zero. However, buying $B$ would yield a loss because the market maker would assume that the investor had received signal $b$ and would set a price that exceeds the investor's expected value of $B$. Consequently, it is optimal for the investor to trade sincerely, that is, to buy Asset $A$ (recall that investors do not have the option not to trade). Likewise, after a signal $s^{i}=b$ only an investment in asset $V^{i}=B$ is optimal. To summarize:

Proposition 1 (Dasgupta and Prat [2008], section 3). In the absence of reputational concerns, investors always follow their signal and trade sincerely, that is, $V^{i}=A$ if $s^{i}=a$ and $V^{i}=B$ if $s^{i}=b$ for all $i$. Prices are as in Table 1 .

\section{Investors with reputational concerns}

We now augment the model as outlined in the sections Basic Structure and No Reputational Concerns of Investors by reputational concerns of investors. More precisely, in addition to the payoff from buying a certain asset, at date $t=4$ each investor $i$ receives some wage $r^{i}$ that is determined at the end of the game, that is,

$$
\pi_{R}^{i} \equiv \pi_{I}^{i}+r^{i}
$$

Dasgupta and Prat [2008] consider the case that investors are fund managers and that the wage $r^{i}$ is given

Table 1. Market prices for assets A and B.

\begin{tabular}{lccc}
\hline$t$ & $H^{t}$ & $p_{A}^{t}$ & $p_{B}^{t}$ \\
\hline 1 & - & 7.0 & 7.0 \\
2 & A & 8.4 & 5.0 \\
2 & B & 5.0 & 8.4 \\
3 & AB or BA & 7.0 & 7.0 \\
3 & AA & 9.3 & 3.0 \\
3 & BB & 3.0 & 9.3 \\
\hline
\end{tabular}

Note: Like in the experiment, prices have been rounded to the first decimal. by an outside market's posterior belief that investor $i$ is a good type (i.e., an investor whose signal has informational content). The outside market (i.e., potential future employers) observes the entire history $H^{4}$ of trades and prices as well as the realized true state of the world $v$ (i.e., which of the two assets is successful). Consequently, in contrast to the section No Reputational Concerns of Investors, investors have an incentive to be perceived as a good type. It will turn out that, for Investor 3, it is optimal to disregard his private signal and to herd whenever both predecessors have bought the same asset.

The intuition is as follows: If early investors follow their signal, the price incorporates their private information and moves towards the true liquidation value. Over time, however, price movements become smaller. In particular, profits from trading according to one's signal stay zero, while profits from trading against one's signal stay negative, but decrease in absolute terms. At the same time, a trader who observes a signal contrarian to earlier price movements (and, hence, contrarian to the most likely outcome of the asset) faces endogenous reputational costs: if they would follow their signal, with a high probability the asset they buy would turn out to be worthless and they would be perceived as a bad investor who had received an uninformative signal. Thus, as prices become sufficiently precise (and differential profits from trading $A$ respectively $B$ sufficiently small), investors start to follow predecessors out of reputational concerns.

Wage setting process by principals. In practice, whether reputational herding indeed emerges depends not only on the behavior of investors, but potentially also on the wage-setting behavior by the outside market. Consequently, while Dasgupta and Prat [2008] assume that an investor's wage is equal to their conditional expected productivity, we consider an explicit wage setting process (which yields the same theoretical prediction). In particular, investor $i$ 's wage is determined in a sealed-bid, firstprice auction among six risk-neutral, profit-maximizing "principals," where investor $i$ 's wage $r^{i}$ is determined by the highest bid. The sequence of events is identical to the section Basic Structure up to date $t=3$. As can be observed in Figure 2, it only differs from $t=4$ onward.

Principals can observe the entire history of trades and prices as well as the realized true state of the world $v$. The winning principal has to pay his bid and additionally gets 20 points if and only if investor $i$ happens to be good (otherwise he gets no additional points). ${ }^{15}$ The remaining five principals get a payoff of zero each.

If, at date 4, principals hold a common belief $\gamma$ that investor $i$ is of good type, the principals' bidding strategies in the symmetric equilibrium of the first-price auction are $20 \cdot \gamma$ (i.e., bids are equal to the respective 
investor's "expected value"). ${ }^{16}$ Hence, in analogy to Dasgupta and Prat [2008], in equilibrium the respective investor $i$ receives a reputational payoff of $r^{i}=20 \cdot \gamma \cdot{ }^{17}$

Dasgupta and Prat [2008] show that the belief $\gamma$ that principals hold about a given investor only depends on this investor's equilibrium strategy and the realized true state of the world (but not on the behavior of other investors). Intuitively, this is the case because principals can observe which of the assets turns out to be successful, and investors' signals are mutually independent given the true state of the world $v$ (see Dasgupta and Prat [2008], Proof of Proposition 1). Consequently, (with one exception to be discussed below) equilibrium wage bids take on two values only: ${ }^{18}$ They are equal to 12.86 if the respective investor chose the successful asset, and they are equal to 3.33 if the respective investor chose the unsuccessful asset. The exception are the wage bids for an Investor 3 who has invested in the same asset as both of his or her predecessors (i.e., if $H^{4} \in\{A A A, B B B\}$ ). Such an investor engages in reputational herding, and hence their behavior is uninformative. As, from an ex ante perspective, both types of the investor are equally likely, such an Investor 3 receives a wage offer of $0.5 \cdot 20=10$.

Market prices set by the market maker. The possibility of herding raises an issue with respect to price setting by the market maker in the experiment. From a theoretical perspective, it will turn out that, even in the presence of reputational concerns, both Investor 1 and 2 trade sincerely in equilibrium. Consequently, for them, a profit-maximizing market maker will set asset prices as spelled out in Table 1 . However, for the case of Investor 3, the market maker will suspect herd behavior if $H^{3} \in\{A A, B B\}$, and, in this case, a profit-maximizing market maker would confront Investor 3 with market prices that deviate from Table 1 . In the experiment, market prices that differ across treatments would, however, be problematic as earlier studies have shown that price levels per se influence subjects' inclination to follow their own signal (see, e.g., Cipriani and Guarino [2005], Drehmann, Oechssler and Roider [2005]). In particular, there is evidence for contrarian behavior, where subjects are more likely to act against their signal, if prices are higher. This price effect would make it difficult to compare our treatments with and without reputational concerns. To rule out this confounding effect, we assume that even if investors' payoffs are given by Equation 3, the market maker sets market prices according to Table $1 .{ }^{19}$ In Appendix A, we illustrate that theoretical predictions with respect to the behavior of investors and principals remain unaffected by this assumption. ${ }^{20}$ As a theoretical benchmark in the presence of reputational concerns, we focus on Dasgupta and Prat's [2008] "most revealing equilibrium," in which investors maximally condition their trades on their private information (see Dasgupta and Prat [2008], Section 4.1): ${ }^{21}$

Proposition 2 (Dasgupta and Prat [2008], proposition 4). Assume that market prices are as in Table 1 and that investors have reputational concerns. Then, in the most revealing equilibrium, Investors 1 and 2 trade sincerely. Investor 3 trades sincerely unless both of his or her predecessors have invested in the same asset, in which case he or she herds. The (symmetric) wage bids submitted by the principals for investor $i$ are equal to (a) 10 if $i=3$ and $H^{4} \in$ $\{A A A, B B B\}$, and (b) otherwise they are equal to 12.86 (3.33) if investor i has bought the successful (unsuccessful) asset.

\section{Experimental design}

\section{Recruitment and subject pool}

The experiment was conducted in five sessions, which ran in May and June 2011 in the AWI Lab at the University of Heidelberg. Participants were recruited randomly via Orsee (Greiner [2004]) from AWI Lab's subject pool of persons who had indicated their interest in participating in economic experiments. In total, 90 subjects participated; 18 in each session. None of the subjects had participated in experiments on either herd behavior or reputational effects before. Each session lasted approximately 120 minutes. Participants earned 13.95 Euro on average. Altogether, 44 women (48.89\%) and 46 men participated. The average age was 21.68 years, and the average number of semesters studied 3.75. Of the participants, $35.6 \%$ were economics majors while the secondlargest group consisted of law students (12.22\%). The entire experiment was paper-and-pencil based.

\section{Implementation}

Upon entering the laboratory, all 18 participants of a given session were informed that investment decisions in two completely independent rounds had to be taken. A translation of the experimental instructions can be found in Appendix B.

In the first round, subjects played a treatment investment, and in the second round they played a treatment reputation. The (benchmark) treatment investment corresponds to the setting without reputational concerns described in the section No Reputational Concerns of Investors. That is, all subjects acted as investors, their payoff function was given by Equation 2, and this was common knowledge among participants. Treatment reputation corresponds to the setting with reputational concerns of investors described in the section Investors with Reputational Concerns. Subjects learned about the details of treatment 
reputation only after they had completed the first round. In each session of treatment reputation, 6 randomly selected subjects acted as principals while the remaining 12 subjects acted as investors. Investors' payoff functions were given by Equation 3, principals made wage offers for investors as described in the section Investors with Reputational Concerns, and again this was common knowledge among participants. In order to ensure that both investors and principals were informed about the entire (information) structure of the game, all subjects received identical instructions. To achieve comparability, investors received identical decision sheets in both rounds of the experiment. ${ }^{22}$ As discussed in the sections No Reputational Concerns of Investors and Investors with Reputational Concerns, in both treatments market prices for the two assets were set according to Table $1 .^{23}$

Both rounds of a session had the same basic structure. First, the instructions for the respective round were handed to subjects and read out aloud by the experimenter. Afterward, the experimenter additionally explained the main features of the respective round via a flip chart to subjects. Subsequently, to check whether the experimental setup was clear, a questionnaire regarding details of the setup had to be answered. Only after all subjects had filled out the questionnaire correctly were decision sheets distributed and filled out by the subjects. After this, the respective round ended.

Only after the second round, subjects learned their payoffs. They also answered a postexperimental questionnaire, where we requested demographic information, asked questions about the experiment, and elicited subjects' degree of risk aversion. Finally, payments were privately handed out to subjects, after which the experiment ended.

\section{Strategy method to elicit subjects' decisions}

To elicit subjects' decisions, the strategy method was used. This design choice (together with the choice to consider sequences of three investors) was driven by the following considerations. As discussed in the section Investors with Reputational Concerns, in the presence of reputational concerns theory suggests sincere trading by Investors 1 and 2, and it suggests herding by Investor 3 only if both of his or her predecessors have bought the same asset. Hence, if we would not have employed the strategy method, only the decisions of subjects who (a) act as Investor 3 and (b) face a history of earlier decisions $H^{3} \in\{A A, B B\}$ would have been informative with respect to the presence of reputational herding. In order to economize on the size of the subject pool, we therefore have used the strategy method. Given this design choice, we restrict attention to sequences of three investors in order to limit the number of decisions each subject has to make.
Translations of the decision sheets that investors and principals had to fill out can be found in Appendix B. When acting as an investor, the respective subject was asked to state decisions $V^{i}$ for all $i \in\{1,2,3\}$, for all possible histories of prices and predecessors' decisions, and all possible own signal realizations he or she might observe. That is, the respective subject was asked to state a decision for every information set at which an investor might have to make a decision. For example, when acting as an investor the subject was asked to imagine that they were Investor 1 and to state their decision for both the cases that they receive the signal $s^{1}=a$ and $s^{1}=b$. Likewise, the subject was asked to imagine they were Investor 2 and to state their (in total, 4) decisions depending on whether their predecessor had chosen $A$ or $B$ and depending on whether their own signal was $a$ or $b$. In a similar vein, as Investor 3 they had to state 8 decisions. Subjects who acted as principals in treatment reputation were asked to submit a bid for each investor $i \in\{1,2,3\}$ for each possible history of decisions and prices the respective investor might have observed, and for each possible realization of the state of the world. ${ }^{24}$

\section{Payments}

Subjects received a showup fee of 4 Euro about which they were informed at the beginning of the experiment. Subjects were furthermore told that, depending on their success in the experiment, they could earn additional money, where each additional point (our experimental currency) paid out 0.20 Euro. In each of the two rounds, each subject (investors in treatment investment, and investors and principals in treatment reputation) received an initial endowment of 20 points. Except for the showup fee, the exact amount earned was revealed at the end of the experiment only (and subjects were aware of this).

As we employed the strategy method, in each of the two rounds each subject's payoff depended on one randomly chosen decision, and we took care to explain in detail to subjects how individual payoffs were calculated. In the following, we describe how individual payoffs were calculated and, in Appendix C, we provide an example. In particular, at the end of the experiment and independently for each of the two rounds, payments were determined as follows: By making draws from urns, (a) we randomly allocated investors into groups of three subjects and randomly assigned the roles of Investor 1, 2, and 3, and (b) according to the probabilities described above, for each of the investor groups, we randomly determined the successful asset and each investor's type and signal. ${ }^{25}$ Given this information, for each of the investor groups, we are then able to obtain the decision of Investor 1 from the respective subject's decision sheet and 
to calculate their payoff from their investment decision (see Equation 2 above). In a second and third step, we then obtain the decisions (and calculate the payoffs) of Investors 2 and 3 in an analogous way (given the decisions of Investor 1 , and of Investors 1 and 2, respectively). This concludes the determination of payoffs in treatment investment.

In treatment reputation, the above procedure left us with a decision history and a successful asset for each of the four investor groups in a given session of this treatment. By looking at the decision sheets of principals, we were hence able to determine the highest bid for each investor (i.e., their wage). Given the respective investor's type, we were also able to determine the principals' payoffs from the auction for the respective investor: only the winning principal had to pay the bid and, if the investor was a good type, the winning principal earned 20 points. All other principals earned 0 from the respective auction. ${ }^{26}$

\section{Results}

In this section, the results of the experiment are presented. In the first subsection, we discuss the evidence for reputational herding by comparing treatments reputation and investment. The second subsection documents substantial imitative behavior among investors that cannot be explained by Dasgupta and Prat's [2008] model. Finally, in the third subsection, we compare the actual wage setting by principals with various benchmarks, and we study the incentives for reputational herding the actual wage setting creates.

\section{Evidence on reputational herding}

For both treatment investment and reputation, Table 2 depicts the fraction of subjects that behave in line with the theoretical prediction at a given information set of the game (where an information set is characterized by

Table 2. Fraction of investors behaving in line with the theoretical prediction.

\begin{tabular}{cccc}
\hline & & \multicolumn{2}{c}{ Treatment } \\
\cline { 3 - 4 } Investor & Information Set & Investment (\%) & Reputation (\%) \\
\hline 1 & $X$ & 91.66 & 95.83 \\
2 & $X x$ & 85.00 & 89.17 \\
2 & $X y$ & 79.45 & 80.00 \\
3 & $X X X$ & 81.11 & 86.67 \\
3 & $X X y$ & 56.33 & 41.67 \\
3 & $X Y y$ & 86.67 & 90.00 \\
3 & $X Y X$ & 94.45 & 95.00 \\
\hline
\end{tabular}

Note: $\mathrm{N}=90(\mathrm{~N}=60)$ in treatment investment (reputation). With respect to the information available to subjects, capital letters refer to the observed decisions of predecessors (i.e., $X, Y \in\{A, B\}$, where $X \neq Y$ ), and small letters indicate the own signal (i.e., $x, y \in\{a, b\}$, where $x=a$ if $X=A, x=b$ if $X=B$, $y=a$ if $X=B$, and $y=b$ if $X=A$ ). the predecessors' choices and the own signal). Note that we pool information sets that differ in labeling only, and hence are symmetric. For example, in Table $2 A A b$ and $B B a$ are both subsumed under $X X y .{ }^{27}$ More formally, in the following we describe information sets by combinations of capital letters and small letters where capital letters refer to the observed decisions of predecessors (i.e., $X, Y \in\{A, B\}$, where $X \neq Y)$ and small letters indicate the own signal (i.e.,. $x, y \in\{a, b\}$, where $x=a$ if $X=A, x=b$ if $X=B, y=a$ if $X=B$, and $y=b$ if $X=A$ ).

A first inspection of Table 2 reveals that at all information sets except $X X Y$ behavior is remarkably close to the theoretical prediction of subjects following their own signal independent of the investment decisions of predecessors. Indeed, in treatment investment (treatment reputation) $86.39 \%(89.44 \%)$ of decisions are in line with theory if one averages over all information sets except $X X y{ }^{28}$ In treatment reputation, Dasgupta and Prat [2008] predict that Investor 3 herds at information set $X X Y$ (i.e., if the decisions of both of his or her predecessors conform). And, indeed, Table 2 shows that $41.67 \%$ of subjects disregard their own signal and follow the lead of predecessors' decisions instead. Two observations with respect to behavior at information set $X X Y$ are, however, surprising. First, even in treatment reputation, a majority of subjects still follows its own signal. Second, even in treatment investment (where, according to Dasgupta and Prat [2008], acting against one's signal is never optimal) a substantial fraction of subjects disregards its private information. It turns out that, both in treatment reputation and in treatment investment, behavior differs significantly at information set $X X Y$ compared to all other information sets (at the $1 \%$ level). ${ }^{29}$

Table 3 investigates behavior at information set $X X Y$ in more detail. There, we restrict attention to the $60 \mathrm{sub}-$ jects that serve as investors in both treatments. As Table 3 indicates, a substantial number of subjects either follow their own signal in both treatments (i.e., in both treatments choose $Y$ ) or follow the lead of their predecessors in both treatments (i.e., always choose $X$, which, according to Table 3, holds for 43 subjects). At information set $A A b(B B a)$ only $4(3)$ out of 60 subjects act in line with

Table 3. Number of investors choosing asset $X$ respectively $Y$ at information set XXY.

\begin{tabular}{lcccc}
\hline & & \multicolumn{3}{c}{ Reputation } \\
\cline { 3 - 5 } & & $\mathrm{X}$ & $\mathrm{Y}$ & Sum \\
\hline \multirow{2}{*}{ Investment } & $\mathrm{X}$ & 43 & 14 & 57 \\
& $\mathrm{Y}$ & 7 & 56 & 63 \\
& Sum & 50 & 70 & 120 \\
\hline
\end{tabular}

Note: $\mathrm{N}=60$ in both treatments (i.e., all subjects except those who acted as principals in treatment reputation). 
theory in both treatments. Behavior at $X X y$ does not differ significantly between treatments according to a McNemar change test. ${ }^{30}$

To summarize, it is indeed in the situations predicted by Dasgupta and Prat [2008] that a substantial fraction of subjects disregards its own information in treatment reputation (and, hence, follows an established trend). However, it is surprising that a similar fraction of investors engages in the same behavior in treatment investment, where reputational incentives are absent. This finding is studied in more detail in the next subsection. ${ }^{31}$

\section{Evidence on imitative behavior by investors}

The finding that even in treatment investment a substantial fraction of subjects (nearly half) disregards its own signal at information set $X X Y$ is indicative of imitative behavior on the part of investors, which cannot be explained by Dasgupta and Prat [2008]. If such imitative behavior is indeed prevalent and has been anticipated by principals, it might have affected principals' wage offers. In turn, this might have affected the reputational incentives faced by investors. This might potentially help to explain the apparent lack of reputational herding in treatment reputation.

Consequently, in a next step, we provide evidence on imitative behavior among investors. To do so, we first look at the behavior of Investor 2, who, independent of the treatment, should always follow their own signal. However, as Table 2 indicates, Investor 2 is less likely to trust their private information at information set $X y$ than at information set $X x$ (in treatment investment: $79.45 \%$ vs. $85.00 \%$, and in treatment reputation: $80.00 \%$ vs. $89.17 \%)$. That is, if the predecessor's decision contradicts their own private information, some investors seem to imitate their predecessor. ${ }^{32}$ That there is indeed significant imitative behavior among subjects is confirmed by a regression analysis. In Table 4, we report on a probit estimation where the dependent variable is equal to 1 if $A$ is chosen and equal to 0 if $B$ is chosen. As an explanatory variable, we include signal, which is an indicator variable that is equal to 1 if the signal observed by the respective investor is $a$, and that is equal to 0 if the signal observed by the respective investor is $b$. If there were no imitation, only the variable signal would affect investors' behavior. One way to measure the potential influence of predecessors' actions is the explanatory variable history (which is not defined for Investor 1 who does not have predecessors). ${ }^{33}$ In the case of Investor 2, history is equal to $1(-1)$ if the respective predecessor has chosen $A(B)$. In the case of Investor 2 , history is equal to $2(-2)$ if both predecessors have chosen $A(B)$, and it is 0 if the predecessors' actions do not agree. Alternatively, we
Table 4. Evidence on imitative behavior in treatment investment.

\begin{tabular}{lccccc}
\hline & 1 & 2 & 3 & 4 & 5 \\
\hline signal & $0.833^{* * *}$ & $0.644^{* * *}$ & $0.592^{* * *}$ & $0.623^{* * *}$ & $0.614^{* * *}$ \\
& $(0.040)$ & $(0.044)$ & $(0.032)$ & $\begin{array}{c}(0.032) \\
(0.033)\end{array}$ \\
history & & & & $\begin{array}{c}0.077^{* * *} \\
(0.025)\end{array}$ \\
decision1 & & & & & $0.229^{* * *}$ \\
& & & & & $(0.058)$ \\
decision2 & & & & & $0.109^{* * *}$ \\
& & & & & $(0.057)$ \\
Observations & 180 & 360 & 720 & 1080 & 720 \\
Log-likelihood & -50.71 & -168.44 & -364.41 & -516.56 & -346.02 \\
Pseudo-R & 0.5927 & 0.3249 & 0.2698 & 0.3100 & 0.3067 \\
\hline
\end{tabular}

Note: Probit estimates, where all regressions include a constant and where coefficients represent marginal effects. The regression analyzes behavior of investors in treatment investment $(\mathrm{N}=90)$. Robust standard errors (clustered at the subject-level) are shown in parentheses. ${ }^{* * *},{ }^{* *}$, and ${ }^{*}$ indicate significance at the $1 \%, 5 \%$, and $10 \%$ level, respectively. Columns 1,2 , and 3 consider behavior of Investor 1, Investor 2, and Investor 3, respectively. Column 4 pools observations from Investors 2 and 3 , and column 5 considers Investor 3 only.

study the explanatory variable decision1 (decision2), which is an indicator that is equal to 1 if investor $1^{\prime} s$ (investor $2^{\prime} s$ ) decision is $A$, and that is equal to 0 if the respective investor's decision is $B$.

In the regression analysis, we restrict attention to treatment investment because there, from a theoretical perspective, subjects should always follow their own signal. In column 1 of Table 4, we regress the decision of Investor 1 on his signal. Columns 2 and 3 repeat the same exercise for Investors 2 and 3, respectively. In these regressions, we find a highly significant effect of the own private information (where standard errors are clustered at the subject level). Nevertheless, coefficients seem to be declining in the position of the investor, which might be indicative of the fact that subjects are also affected by factors other than their own signal. In column 4 , we pool observations from Investors 2 and 3 (who potentially might engage in imitative behavior). There, we again find a highly significant effect of the own signal. However, history also has a highly significant effect that demonstrates that, contrary to what theory would predict, these investors tend to imitate their predecessors. In column 5, we investigate whether Investor 1 or Investor 2 has a stronger influence on Investor 3's behavior. In this regression, we find a highly significant influence of Investor 1 and a marginally significant influence of Investor 2. Thus, Investor 3 seems to be more inclined to follow earlier rather than later decisions. ${ }^{34}$

Taken together, the findings of Table 4 provide strong evidence for imitation that cannot be explained by Dasgupta and Prat's [2008] model of reputational herding. This finding is interesting in the light of the earlier experimental literature on herding in financial markets. For example, various experiments studying informational cascades in markets with flexible prices find that imitation seems to occur only 
rarely (see, e.g., Cipriani and Guarino [2005], Drehmann, Oechssler and Roider [2005]). ${ }^{35}$

\section{Wage setting by principals}

Having documented imitative behavior on the part of investors, we now turn to the wage setting of principals. Was their wage setting in line with theory? Did principals correctly anticipate the actual behavior of investors in the experiment? And if yes, did the principals' wagesetting behavior lead to reduced incentives for reputational herding in treatment reputation?

Two benchmarks: equilibrium wages and behavioral wages. To evaluate the actual wage setting by principals in the experiment, we calculate two benchmark wages. The first benchmark is the equilibrium wages $r^{e q}$ that are predicted by theory (see Proposition 2). As a second benchmark, we calculate behavioral wages $r^{\text {beh }}$ that would optimally have been set by profit-maximizing principals if they had correctly anticipated the actual behavior of investors in the experiment. In order to calculate the behavioral wages $r^{\text {beh }}$, we proceed as follows. First, from the actual frequencies with which the two types of Investors 1, 2, and 3 follow their own signal in treatment reputation, we calculate the empirical frequencies of facing a good investor (given a certain combination of history of trades and realized value of the asset). Multiplying these empirical frequencies with the good investor's value of 20 points, we arrive at the behavioral wages $r^{\text {beh }}$.

Wage setting by principals relative to the benchmarks. In a first step, we consider the wages offered to Investors 1 and 2. From a theoretical perspective, these investors always trade sincerely, and the equilibrium wage $r^{e q}$ they receive depends on the success respectively failure of the investment only (see Proposition 2). As illustrated in Table 5, on average, behavioral wages offered to these investors would be less extreme than equilibrium wages. That is, behavioral wages would be lower (higher) than equilibrium wages when the asset is successful (unsuccessful). Given that the partially imitative behavior of investors makes it more difficult to gauge the investor's type from the outcome of the game, it does not seem surprising that behavioral wages would be closer to 10 (which would be the optimal wage offer if one would not have any additional information except for the prior probability of facing a good type). In

Table 5. Average wages offered to investors 1 and 2.

\begin{tabular}{lrrrr}
\hline Purchased Asset is & \multicolumn{1}{c}{$r^{\text {eq }}$} & $r^{\text {beh }}$ & \multicolumn{1}{c}{$r^{\text {all }}$} & $r^{\max }$ \\
\hline Unsuccessful & 3.33 & 4.27 & 2.17 & 6.79 \\
Successful & 12.86 & 11.83 & 10.34 & 16.15 \\
\hline
\end{tabular}

Table 6. Average wages offered to investor 3.

\begin{tabular}{llrrrr}
\hline Purchased Asset is & History of Trades & $r^{\text {eq }}$ & $r^{\text {beh }}$ & $r^{\text {all }}$ & $r^{\text {max }}$ \\
\hline Unsuccessful & $=X X X$ & 10.00 & 5.83 & 3.40 & 10.10 \\
& $\neq X X X$ & 3.33 & 4.69 & 2.37 & 6.80 \\
Successful & $=X X X$ & 10.00 & 10.01 & 9.42 & 16.10 \\
& $\neq X X X$ & 12.86 & 11.30 & 10.31 & 16.53 \\
\hline
\end{tabular}

order to evaluate actual wage setting, in Table 5, we report $r^{\text {all }}$ (which is the average wage offer when considering all principals) and $r^{\max }$ (where we only consider the maximum wages, i.e., the wages offered by winning principals). As Table 5 documents, on average, $r^{\text {all }}$ is somewhat lower than the benchmarks $r^{e q}$ and $r^{\text {beh }}$, while $r^{\max }$ overshoots both benchmarks. However, in line with the benchmark wages, $r^{\text {all }}$ and $r^{\text {max }}$ are significantly higher in case of success than in case of failure of the investment (according to Wilcoxon signed ranks tests at the $1 \%$ level and 5\% level, respectively). ${ }^{36}$

In a second step, we consider wages offered to Investor 3 , which are displayed in Table 6 . When theory predicts herding, $r^{e q}$ is equal to 10 (because in this case the investor's decision is uninformative about his type). Otherwise, equilibrium wages only vary in the success or failure of the investment. In line with both benchmark wages, principals seem to consider the history of trades $X X X$ as less informative of the respective investor's type than other histories of trade (because at histories of trade other than $X X X$ wages are further away from 10). ${ }^{37}$ An interesting observation with respect to behavioral wages emerges if the history of trades is given by XXX. Then, the equilibrium prediction for the wage is 10 independent of the investment's success. While in case of a successful investment the behavioral wage $r^{b e h}$ is almost identical to this prediction, in case of an unsuccessful investment $r^{\text {beh }}$ is considerably lower. Hence, in contrast to what is predicted by theory, even in these situations the failure of the investment seems to be predictive of the investor's type. More importantly, across the various settings considered in Table 6, for both $r^{\text {all }}$ and $r^{\max }$ the relative ordering of the wages is identical to the relative ordering of $r^{b e h}$ : Investor 3 fetches the lowest (highest) wage when the history of trade is not $X X X$ and when their investment is unsuccessful (successful). As in the case of the wages offered to Investors 1 and 2, the wages $r^{\text {all }}\left(r^{\max }\right)$ that are offered to Investor 3 somewhat undershoot (overshoot) the benchmark wage $r^{\text {beh }}$. Nevertheless, principals' actual wage-setting behavior comes relatively close to the benchmark $r^{\text {beh }}$.

Are there different behavioral types among the principals? One might suspect that principals who themselves are prone to imitative behavior might set wages differently from other principals. We investigate this issue by 
Table 7. Average wages $r^{\text {all }}$ offered to investor 3 by imitators and nonimitators.

\begin{tabular}{lccccc}
\hline & \multicolumn{4}{c}{ Purchased Asset Is } \\
\cline { 2 - 3 } & \multicolumn{2}{c}{ Unsuccessful } & & \multicolumn{2}{c}{ Successful } \\
\cline { 2 - 3 } \cline { 5 - 6 } History of Trades & Nonimitators & Imitators & & Nonimitators & Imitators \\
\hline \multirow{2}{*}{$X X X$} & 3.36 & 3.50 & & 9.64 & 8.81 \\
$X X Y$ & 1.80 & 1.38 & & 9.27 & 11.94 \\
$X Y Y$ & 2.86 & 3.31 & & 10.18 & 9.94 \\
$X Y X$ & 2.25 & 3.00 & & 11.18 & 9.81 \\
\hline
\end{tabular}

Note: A principal is labeled an imitator if in treatment investment he or she bought Asset $A$ at information set $A A b$ and bought Asset $B$ at information set $\mathrm{BBa}$, which applies to 8 (out of a total of 30 ) principals. All other principals are labeled as nonimitators.

using data from treatment investment, where the principals of treatment reputation acted as investors. We label a principal as an imitator if, in treatment investment, they bought Asset $A$ at information set $A A b$ and bought Asset $B$ at information set $B B a$. This applies to 8 of the principals. The remaining 22 principals are labeled as nonimitators. In order to study potential behavioral differences between these two types of principals, we focus on the wages offered to Investor 3 . We do this to explore two issues: First, do different principals react differently to Investor 3 following his or her predecessors? And, second, what role does the ultimate success of Investor 3 's decision play? While, due to large variances, differences are, in general, not statistically significant, some suggestive patterns do emerge nonetheless (see Table 7, which displays average wages $r^{\text {all }}$ ).

On average, principals offer higher wages to successful investors than to unsuccessful investors. With one notable exception (discussed below), imitators tend to punish failure somewhat less and reward success somewhat less than nonimitators do. That is, imitators seem to offer slightly higher (lower) wages than nonimitators if the asset is unsuccessful (successful). This could suggest that imitators perceive success (respectively failure) as less informative of the investor's type than nonimitators do. The interesting exception to this emerges if the history of trades is given by XXY: If Investor 3 decides to make an investment that contradicts both of his or her predecessors, imitators seem to condition their wage offers on the success or failure of the investment decision more strongly than nonimitators do. That is, imitators seem to deem acting against an established trend as more informative about the respective investor's type than nonimitators do. Moreover, independent of the success of the investment, nonimitators reward herding (in the sense that they make higher wage offers to Investor 3 given a history of trades $X X X$ than given a history of trades $X X Y: 3.36$ vs. 1.80 , and 9.64 vs. 9.27). This is not the case for the imitators among the principals (where in case of success of the investment, we have 8.81 vs. 11.94).

Reputational incentives for Investor 3. A key question is whether the actual wage-setting behavior of the principals in the experiment generates incentives for Investor 3 to engage in reputational herding. In order to investigate this issue, we look at each of the information sets that Investor 3 might face (i.e., $X X Y, X X x, X Y x$, and $X Y y$ ). For each of these four cases, we derive the difference between Investor $3^{\prime}$ s expected payoff when he or she does not follow their signal and Investor 3 's expected payoff when he or she does follow their signal. We calculate these payoff differences under various assumptions on what Investor 3 believes about the behavior of Investor 1 , Investor 2, and the principals.

In column 1 of Table 8 , we report the payoff differences predicted by Proposition 2. For this case, column 1 indicates that Investor 3 should engage in reputational herding at information set $X X Y$ (yielding him or her a payoff that is 1.51 points higher than when trading sincerely). Investor 3 should follow their signal otherwise (as indicated by the negative payoff differences). ${ }^{38}$ In columns 2 and 3 of Table 8, we assume that Investor 3 holds the belief that Investors 1 and 2 always act in line with theory (i.e., always follow their signal). However, with respect to the wage offers, we assume that Investor 3 correctly anticipates the actual wage-setting behavior by principals: $r^{\text {all }}$ (column 2 ) respectively $r^{\max }$ (column 3). Interestingly, in both columns 2 and 3, reputational incentives remain intact: an Investor 3 holding such beliefs should still herd at information set $X X Y$, but not otherwise.

In columns 4 and 5 of Table 8 , we assume that Investor 3 not only correctly anticipates actual wage setting by

Table 8. Differences in expected payoffs of investor 3 from not following respectively following his own signal under various beliefs on the behavior of investor 1 , investor 2 , and the principals.

\begin{tabular}{|c|c|c|c|c|c|c|}
\hline \multirow[b]{2}{*}{ Information Set } & \multicolumn{3}{|c|}{$\begin{array}{l}\text { Investor } 3 \text { Assumes } \\
\text { Sincere Trading by Investors } 1 \text { and } 2\end{array}$} & \multicolumn{3}{|c|}{$\begin{array}{c}\text { Investor } 3 \text { Correctly } \\
\text { Anticipates Actual Behavior by Investors } 1 \text { and } 2\end{array}$} \\
\hline & $r^{e q}$ & $\begin{array}{c}2 \\
r^{a l l}\end{array}$ & $r^{3}$ & $\begin{array}{c}4 \\
r^{\text {all }}\end{array}$ & $\stackrel{5}{r^{\max }}$ & $\begin{array}{c}6 \\
r^{\text {beh }}\end{array}$ \\
\hline$X X y$ & 1.51 & 0.45 & 0.85 & -1.89 & -0.38 & -2.76 \\
\hline$X X X$ & -10.50 & -8.93 & -11.14 & -7.14 & -9.23 & -3.30 \\
\hline$X Y X$ & -7.81 & -6.31 & -6.81 & -7.59 & -8.12 & -6.88 \\
\hline$X Y y$ & -7.81 & -6.14 & -6.91 & -5.68 & -6.35 & -4.75 \\
\hline
\end{tabular}


principals, but that they also correctly anticipate the actual behavior of Investors 1 and 2 in the experiment. That is, we assume that Investor 3 anticipates the actual frequencies with which Investors 1 and 2 do not trade sincerely. In this case, given a certain history of his or her predecessors' decisions, Investor 3 draws correct inference about the success probabilities of the two assets. Columns 4 and 5 of Table 8 reveal that, if Investor 3 held such correct beliefs, reputational incentives to herd would disappear. This is so because not following the own signal would always lead to a negative payoff. In column 6 of Table 8, we investigate whether incentives for reputational herding would reemerge if Investor 3 held correct beliefs with respect to the behavior of the other investors, and if, in addition, he or she expected optimal wage setting by principals (i.e., wage offers $r^{\text {beh }}$ ). This is not the case because not following their own signal would again always yield a negative payoff.

To summarize, if we assume that Investor 3 anticipates the actual (partly imitative) behavior of earlier investors, then the monetary incentives for reputational herding disappear (see columns 4-6 of Table 8). Hence, the apparent lack of reputational herding seems to be a consequence of the noisy behavior of early investors who do not always follow their private signal. If earlier decisions do not reveal the underlying private information, observing an established trend is less indicative of the potential success of the investment. Hence, acting against the trend carries a smaller loss in reputation than what theory would suggest (because acting against the trend does less strongly suggest that the respective investor is a bad type). This smaller loss in reputation might lead later investors to refrain from herding.

\section{Conclusion}

The possibility of herd behavior in financial markets has received considerable attention in both the academic literature and the popular press. Various explanations have been put forward why investors might tend to follow existing trends (e.g., social learning, reputational concern, or simply imitation). Purely information-based social-learning arguments have been studied extensively in the theoretical and experimental literature. Reputational concerns of investors as a potential source of herding have received relatively less attention. This seems somewhat surprising given the prominence of reputation-based explanations among practitioners (see, e.g., the epigraph) and given the attention they have received in the empirical literature.

By now, there is a growing theoretical literature on reputational herding. To our knowledge, the present paper is the first one to implement a theory of reputational herding in financial markets in the laboratory. In particular, we consider the model by Dasgupta and Prat [2008], where investors might disregard their private information and follow an existing trend because they worry about later wage offers from an outside job market. Conducting an experiment allows to control for the information that investors hold and for the incentives that they face. This is, in general, not possible in an empirical study.

The intuition behind Dasgupta and Prat [2008] is as follows. They consider a sequential asset market, where investors receive private information with respect to the prospects of two assets. The precision of this signal depends on the investor's unobservable ability type. Early investors will find it optimal to trade sincerely and, as a consequence, the market prices of the assets will move closer toward their true values. Hence, profits from trading become smaller and smaller. At the same time, for later investors, acting against an established trend comes at a cost because it might leave the outside job market with the impression that the respective investor is a bad type (who has received a wrong signal). Hence, the theory predicts that, depending on the history of earlier trades, later investors might optimally disregard their private information and engage in reputational herding.

Whether reputational herding indeed emerges depends on two things. First, whether investors respond to the incentives set by the outside market, and, second, whether the outside job market indeed sets incentives for reputational herding. As a consequence, in the experiment, we consider an explicit wage-setting process where some of the subjects act as principals and make wage offers to investors.

In the experiment, we find that it is indeed in the situations predicted by Dasgupta and Prat [2008] that a substantial fraction of investors follows an established trend. However, this seems to be driven by imitation rather than by reputational herding: A similar fraction of subjects engages in such behavior even in a treatment where there is no outside job market (and where theory would predict sincere trading by all investors). The fact that we document imitation that is not driven by a profit motive seems to be interesting because such behavior has hardly been observed in earlier experiments on herding in financial markets.

In the experiment, wages somewhat undershoot the theoretical prediction while average winning wages somewhat overshoot the theoretical prediction. To investigate the reputational incentives investors have faced in the laboratory, we conduct a thought experiment. If we assume that Investor 3 anticipates the actual (partly imitative) behavior of earlier investors, then the monetary incentives for reputational herding disappear. Hence, the apparent lack of reputational herding might be driven by the rather noisy behavior of early investors: Because early investors do not always follow their private signal, observing an established trend is less indicative of the potential success of the investment. Hence, acting against the trend carries a smaller loss in reputation than what theory suggests (because acting against the trend 
does less strongly imply that the respective investor is a bad type). This smaller loss in reputation might lead later investors to refrain from herding.

This raises the question whether, with a longer sequence of investors than considered in the present experiment, incentives for reputational herding might reemerge. In theory, this could happen even when early investors' decisions do not perfectly reflect their private information: If there is a sufficiently long trend in the same direction, this might still provide sufficiently precise information on the true state of the world. However, sufficiently long trends might not emerge. While the settings are slightly different, experiments on social learning in financial markets (see, e.g., Cipriani and Guarino [2005], Drehmann, Oechssler and Roider [2005]) have documented a strong tendency of investors to engage in "contrarian behavior" (i.e., the higher the market price of an asset, the less likely are investors to buy this asset). As a consequence, even with a longer sequence of investors, asset prices might fail to become sufficiently extreme for reputational concerns to outweigh profits from trading according to one's own information.

In our experiment, all investors were informed in the sense that each investor received a signal that contained some information. ${ }^{39}$ That is, we abstract from completely uninformed investors. In the real world, in many stocks and markets, there will be substantial numbers of uninformed traders whose behavior is unlikely to be random. As a consequence, our present findings mainly apply to stocks respectively markets in which uninformed traders play a limited role. As opposed to heavily traded stocks, this may particularly hold for stocks that are difficult to assess or to arbitrage (see, e.g., Blasco and Ferreruela [2008], Sias [2004], Palomino [1996]). It would be an interesting relevant topic for future experimental research to study how the presence of uninformed traders affects financial market outcomes.

\section{Acknowledgments}

We would like to thank seminar participants at the University of Heidelberg and at the 2012 World Congress of the Game Theory Society in Istanbul. We are also grateful to a referee for helpful comments. This paper was part of Andrea Voskort's $\mathrm{PhD}$ thesis at the University of Heidelberg. It represents the analysis and views of the authors and should not be thought to represent those of the German Federal Financial Supervisory Authority (BaFin), Bonn.

\section{Notes}

1. In Avery and Zemsky [1998], this is the case in a setup with two dimensions of uncertainty and two states of the world. Traders have private information not only about the assets' values, but also about whether some event occurs that changes the value of the asset substantially ("event uncertainty"). While in Avery and Zemsky [1998] herding does not emerge if there is one-dimensional uncertainty with respect to the assets' values only, Park and Sabourian [2011] show that, even in this case, there may be herding if there are more than two states of the world.

2. For other theoretical work on reputational incentives in a financial markets context, see, for example, Villatoro [2009], Dasgupta and Prat [2006], and Huddart [1999].

3. Investors might, for example, have an intrinsic preference for conformity.

4. Herd behavior, in our setup, refers to the case in which investors follow the investment decisions of predecessors regardless of their own signal. In this case, investors' behavior thus does not carry informational value and asset prices do not converge to the true liquidation values.

5. While an experimental approach has its own issues, it has the advantage of being able to control for decision makers' private information and monetary incentives (which is, in general, difficult when working with real financial market data).

6. Of course, as mentioned above, experimental studies might have their own issues such as the external validity of the findings. Hence, both approaches complement each other.

7. Beginning with Anderson and Holt [1997], there is a vast experimental literature on such "information cascades" in settings with fixed prices. These studies, however, do not directly apply to financial markets where prices are flexible. For an overview, see, for example, Weizsacker [2010] or Drehmann, Oechssler and Roider [2007].

8. Note that sufficient complexity of the environment seems to be necessary for information-based herding to emerge: Drehmann, Oechssler and Roider [2005] and Cipriani and Guarino [2005] confirm Avery and Zemsky's [1998] prediction of no herding in a simple financial market with one-dimensional uncertainty over two potential states of the world.

9. See also the experiment by Irlenbusch and Sliwka [2006] where, however, not only career concerns, but also gift-exchange considerations might have affected subjects' behavior.

10. The reasons for considering sequences of three investors are discussed in detail in the section Experimental Design.

11. Dasgupta and Prat [2008] consider the choice between buying or (short) selling a single asset. In line with other experiments on herding in financial markets (see, e.g., Drehmann, Oechssler and Roider [2005], Cipriani and Guarino [2005]) we consider the strategically equivalent choice between buying either $A$ or $B$, which seems to be easier to explain to experimental subjects.

12. In their model, Dasgupta and Prat [2008] assume that a certain fraction of the investors are noise traders whose trading is purely random. For two reasons, we do not include such noise traders. First, this simplification does not affect the theoretical predictions; and, second, it makes it easier to explain the experimental setting to subjects. Note that despite of this simplification, market breakdown is not an issue as, in the experiment, subjects have to buy one of the two assets. The issue of uninformed traders is discussed in more detail in the Conclusion.

13. Note that, in the experiment, investors learn the state and their payoffs only at the very end of the experiment after all decisions have been made.

14. In the presence of reputational concerns (see the section Investors with Reputational Concerns) this will be a useful 
feature because, from a theoretical perspective, "extreme" prices facilitate reputational herding.

15. In case of a tie, each of the highest bidding principals wins with equal probability.

16. To see this, note that in any equilibrium the following has to hold: (a) all bids must be weakly below $20 \cdot \gamma$ (because otherwise the winning bid would lead to a loss), (b) the maximum bid must be equal to $20 \cdot \gamma$ (because otherwise a losing bidder would have an incentive to overbid), and (c) at least two bids must be equal to $20 \cdot \gamma$ (because otherwise the winning bidder would have an incentive to lower his or her bid). Hence, in any equilibrium of the first-price auction at least two principals bid $20 \cdot \gamma$ while the remaining principals bid weakly less than that.

17. Note that in Dasgupta and Prat [2008], the weight of reputational concerns in an investor's payoff function is determined by the parameter $(1-\beta)$, where $\beta$ constitutes the payoff fraction from investing in the asset. By fixing the value of the good investor to 20 and the successful asset's payoff to $10,(1-\beta)$ equals $2 / 3$ in our setup.

18. For a more detailed sketch of Dasgupta and Prat's [2008] argument, see Appendix A.

19. Recall that the role of market maker is played by the experimenter, and hence potential losses are not an issue.

20. As argued above, for a given investor, principals' equilibrium wage bids only depend on (i) investors' equilibrium strategies and (ii) the realized true state of the world. In Appendix A, we show that, given equilibrium wage bidding strategies of principals, equilibrium investment strategies of investors are the same independent of whether one sets market prices according to Table 1 or whether market prices take potential herd behavior by Investor 3 into account.

21. That is, in this equilibrium information is revealed in the fastest possible way in the sense that there is no other (reasonable) equilibrium where, at any date $t$, more information is revealed.

22. Subjects were allowed to keep a copy of their first-round decision sheet as a reference for the second round. Importantly, we made it clear to subjects that second-round decision making did not require recalling first-round decisions.

23. Drehmann, Oechssler and Roider [2005] conduct an experiment on information-based herding in financial markets and document behavior that is quite robust across pricing rules that make different assumptions on the behavior of investors (e.g., pricing rules that allow for different forms of "mistakes").

24. The maximum possible bid for an investor was limited to 20 points.

25. That is, in all of the sessions there were six investor groups in treatment investment and four investor groups in treatment reputation.

26. In both rounds, by experimental design, investors can never lose more money than the initial endowment of 20 points. If, in treatment reputation, a principal wins many auctions and happens to hire a number of investors of bad type, he or she may, in principle, accumulate losses that exceed the initial endowment of 20 points. We excluded this possibility by informing principals that the minimum they could earn were zero points (including the initial endowment). While, in principle, this constraint might have given principals an incentive to overbid relative to what is predicted by Proposition 2, we do not find evidence for this. In fact, looking at all principals, there is even evidence for some underbidding as the average actual wage bid is equal to 6.28 while Proposition 2 would predict an average wage bid of 8.25.

27. For each pair of such symmetric information sets (and for both treatments separately), we conduct McNemar change tests, which all indicate insignificant differences.

28. According to a Wilcoxon signed ranks test (where for each subject, we compare the number of decisions that are in line with theory in treatment investment respectively in treatment reputation), this difference is (marginally) significant with a $p$-value of 0.056 . This might be indicative of some learning effects across rounds.

29. In particular, for both treatments separately, we run pairwise $\mathrm{McNemar}$ change tests comparing behavior at information set $A A b(B B a)$ to behavior at each of the other information sets except $B B a(A A b)$, which all indicate statistical significance at the $1 \%$ level.

30. This remains true if McNemar change tests are separately applied to behavior at information sets $A A b$ respectively $B B a$.

31. The model (on which the theoretical predictions in Propositions 1 and 2 are based) assumes risk-neutrality of investors and principals. In Question 1 of the (nonincentivized) postexperimental questionnaire, we elicited subjects' degree of risk-aversion. The question that we use has been widely employed in survey studies, and it has been validated in laboratory experiments with substantial stakes (see, e.g., Dohmen et al. [2011]). In unreported regressions, we find no significant effect of an investor's degree of risk-aversion on his tendency to follow his signal. This holds both in treatment investment and in treatment reputation. It also holds when we only consider decisions at information sets $X X x$ or $X X Y$.

32. In the postexperimental questionnaire, we asked subjects whether they believe that investors always decide as suggested by their signals. While $77.77 \%$ of subjects thought that Investor 1 behaves this way, $45.55 \%$ thought that Investor 2 behaves this way and only $11.11 \%$ thought that Investor 3 always follows his signal.

33. For a similar approach to capture the influence of predecessors' behavior, see, for example, Drehmann, Oechssler and Roider [2005].

34. On the one hand, this finding is intuitive because the behavior of Investor 2 itself is influenced by the behavior of Investor 1 (see Table 2 and the discussion above). On the other hand, it might be a special feature of the experimental design that there is a well-defined Investor 1 who has access to objective information only (i.e., his or her signal), but who is not affected by decisions of earlier investors (as there are none). Nevertheless, the above finding seems to indicate that early investors (who had less chance to be affected by other investors' behavior) might exert an especially large influence on financial market trends.

35. From a behavioral perspective, it might be possible to explain the behavior of Investor 3 in treatment investment. There is ample evidence that decision makers display asymmetric reactions to good news and bad news in the sense that bad news tends to be ignored (for a recent contribution, see, e.g., Eil and Rao [2011]). It might be that Investor 3 interprets XXx (XXy) as good news (bad news) 
because his own signal confirms (goes against) the preexisting trend. If this is the case, this might help to explain Investor 3's tendency to disregard his signal at information set XXY. At information sets XYy and XYx, it is less obvious whether Investor $3^{\prime}$ s signal is good news or bad news, and indeed the tendency to follow one's own signal does not differ much. Alternatively, it might be that some investors simply have a preference for conformity, which leads them to imitate earlier investors.

36. In case of $r^{\text {all }}\left(r^{\max }\right)$, we compare average wage offers for successful respectively unsuccessful investors at the principal level (at the session level).

37. Only in case of an unsuccessful investment, the difference between wage bids $r^{\text {all }}$ given a history $X X X$ and wage bids $r^{\text {all }}$ given any other history is marginally statistically significant with $p=0.069$ (Wilcoxon signed ranks test that compares average wage bids at the principal level).

38. Note that the history of trades $X X Y$ is off the equilibrium path. In order to calculate the respective payoff difference, we assume that in this case principals hold the off-equilibrium belief that Investor 3 has traded sincerely (which is in line with the assumption made in Dasgupta and Prat [2008]).

39. In particular, this also holds for bad types because investors were assumed to be unaware of their type.

\section{References}

Akerlof, G. and R. Shiller. Animal Spirits: How Human Psychology Drives the Economy, and Why It Matters for Global Capitalism (new ed.). Princeton: Princeton University Press, 2008.

Anderson, L. and C. Holt. "Information Cascades in the Laboratory." American Economic Review, 87, (1997), pp. 847-862.

Avery, C. and P. Zemsky. "Multidimensional Uncertainty and Herd Behavior in Financial Markets." American Economic Review, 88, (1998), pp. 724-748.

Banerjee, A. “A Simple Model of Herd Behavior.” Quarterly Journal of Economics, 107, (1992), pp. 797-817.

Bikhchandani, S., D. Hirshleifer and I. Welch. "A Theory of Fads, Fashion, Custom, and Cultural Change as Informational Cascades." Journal of Political Economy, 100, (1992), pp. 992-1026.

Bikhchandani, S. and S. Sharma. Herd Behavior in Financial Markets: A Review. Policy Working Paper, International Monetary Fund (2000).

Blasco, N. and S. Ferreruela. "Testing Intentional Herding in Familiar Stocks: An Experiment in an International Context." Journal of Behavioral Finance, 9, (2008), pp. 72-84.

Chevalier, J. and G. Ellison. "Career Concerns of Mutual Fund Managers.” Quarterly Journal of Economics, 114, (1999), pp. 389-432.

Cipriani, M. and A. Guarino. "Herd Behavior in a Laboratory Financial Market.” American Economic Review, 95, (2005), pp. 1427-1443.

Daniel, K., D. Hirshleifer and S. H. Teoh. "Investor Psychology in Capital Markets: Evidence and Policy Implications." Journal of Monetary Economics, 49, (2002), pp. 139-209.

Dasgupta, A. and A. Prat. "Financial Equilibrium with Career Concerns." Theoretical Economics, 1, (2006), pp. 67-93.

Dasgupta, A. and A. Prat. "Information Aggregation in Financial Markets with Career Concerns." Journal of Economic Theory, 143, (2008), pp. 83-113.
Dohmen, T., A. Falk, D. Huffman, U. Sunde, J. Schupp and G. Wagner. "Individual Risk Attitudes: Measurement, Determinants, and Behavioral Consequences." Journal of the European Economic Association, 9, (2011), pp. 522-550.

Drehmann, M., J. Oechssler and A. Roider. "Herding and Contrarian Behavior in Financial Markets: An Internet Experiment." American Economic Review, 95, (2005), pp. 1403-1426.

Drehmann, M., J. Oechssler and A. Roider. "Herding With and Without Payoff Externalities: An Internet Experiment." International Journal of Industrial Organization, 25, (2007), pp. 391-415.

Ehrbeck, T. and R. Waldmann. "Why Are Professional Forecasters Biased? Agency Versus Behavioral Explanations." Quarterly Journal of Economics, 111, (1996), pp. 21-40.

Eil, D. and J. M. Rao. "The Good News-Bad News Effect: Asymmetric Processing of Objective Information about Yourself." American Economic Journal: Microeconomics, 3, (2011), pp. 114-138.

Glosten, L. and P. Milgrom. "Bid, Ask and Transaction Prices in a Specialist Market with Heterogeneously Informed Traders." Journal of Financial Economics, 14, (1985), pp. 71-100.

Graham, J. "Herding Among Investment Newsletters: Theory and Evidence." Journal of Finance, 54, (1999), pp. 237-268.

Greiner, B. "An Online Recruitment System for Economic Experiments." In K. Kremer and V. Macho, eds., Forschung und Wissenschaftliches Rechnen. GWDG Bericht 63. Göttingen: Gesellschaft für Wissenschaftliche Datenverarbeitung, 2004.

Hirshleifer, D. and S. H. Teoh. "Herd Behavior and Cascading in Capital Markets: A Review and Synthesis." European Financial Management, 9, (2003), pp. 25-66.

Holmstrom, B. "Managerial Incentive Problems: A Dynamic Perspective." Review of Economic Studies, 66, (1999), pp. 169-182.

Hong, H. and J. Kubik. "Analyzing the Analysts: Career Concerns and Biased Earnings Forecasts.” Journal of Finance, 58, (2003), pp. 313-351.

Hong, H., J. Kubik and A. Solomon. "Security Analysts' Career Concerns and Herding of Earnings Forecasts." RAND Journal of Economics, 31, (2000), pp. 121-144.

Huddart, S. "Reputation and Performance Fee Effects on Portfolio Choice by Investment Advisers." Journal of Financial Markets, 2, (1999), pp. 227-271.

Irlenbusch, B. and D. Sliwka. "Career Concerns in a Simple Experimental Labour Market.” European Economic Review, 50, (2006), pp. 147-170.

Koch, A., A. Morgenstern and P. Raab. "Career Concerns Incentives: An Experimental Test." Journal of Economic Behavior and Organization, 72, (2009), pp. 571-588.

Lamont, O. "Macroeconomic Forecasts and Microeconomic Forecasters." Journal of Economic Behavior and Organization, 48, (2002), pp. 265-280.

Massa, M. and R. Patgiri. "Compensation and Managerial Herding: Evidence from the Mutual Fund Industry." Mimeo, (2007).

Palomino, F. "Noise Trading in Small Markets." Journal of Finance, 51, (1996), pp. 1537-1550.

Park, A. and H. Sabourian. "Herding and Contrarian Behavior in Financial Markets." Econometrica, 79, (2011), pp. 973-1026.

Park, A. and D. Sgroi. "Herding and Contrarian Behavior in Financial Markets: An Experimental Analysis.” Mimeo, (2010).

Scharfstein, D. and J. Stein. "Herd Behavior and Investment." American Economic Review, 80, (1990), pp. 465-79. 
Sias, R. "Institutional Herding." Review of Financial Studies, 17, (2004), pp. 165-206.

Villatoro, F. "The Delegated Portfolio Management Problem: Reputation and Herding." Journal of Banking and Finance, 33, (2009), pp. 2062-2069.

Weizsacker, G. "Do We Follow Others When We Should? A Simple Test of Rational Expectations." American Economic Review, 100, (2010), pp. 2340-2360.

Welch, I. "Sequential Sales, Learning, and Cascades." Journal of Finance, 47, (1992), pp. 695-732.

Welch, I. "Herding Among Security Analysts." Journal of Financial Economics, 58, (2000), pp. 369-39.

\section{Appendix A}

\section{Wages and investment in the presence of reputational concerns}

In this appendix, we illustrate how, building on Dasgupta and Prat's [2008] Proposition 4, the wage bids and investment behaviors as spelt out in Proposition 2 can be derived (given the parameter values we have assumed). In particular, we show that these wage bids and investment behaviors are mutually best replies. (Note that while, in principle, the most-revealing equilibrium may be in mixed strategies, this is not the case given the parameter values assumed here.)

Wage bids. First, suppose an investor's equilibrium strategy tells him to invest sincerely (which will be the case for Investors 1 and 2, and Investor 3 unless both of his or her predecessors have chosen the same asset). In this case, as outlined in the section Investors with Reputational Concerns, the equilibrium wage bids for this investor depend on the ultimate success (respectively failure) of his or her investment only (i.e., whether $V^{i}=v$ or $V^{i} \neq v$ holds). In particular, the potential wage bids $r\left(V^{i}=v\right)$ and $r\left(V^{i}\right.$ $\neq v$ ) equal the conditional probabilities of facing a good type times the good type's value of 20 , where

$$
\begin{array}{r}
r\left(V^{i}=v\right)=\left[\frac{\sigma_{g}}{0.5 \sigma_{b}+0.5 \sigma_{g}} \cdot \frac{1}{2}\right] \cdot 20=12.86 \\
r\left(V^{i} \neq v\right)=\left[\frac{1-\sigma_{g}}{1-0.5 \sigma_{b}-0.5 \sigma_{g}} \cdot \frac{1}{2}\right] \cdot 20=3.33
\end{array}
$$

Hence, $r\left(V^{i}=v\right)>r\left(V^{i} \neq v\right)$, that is, success of the investment is more indicative for a good type.

Second, suppose Investors 1 and 2 have chosen the same asset and Investor $3^{\prime}$ s strategy tells him or her to herd in this case. Then, Investor 3's trade does not reveal any information about their type. Independent of the success of their investment, they will receive wage offers that are determined by the prior probability of being a good type and given by $1 / 220=10$. (Note that, in line with Dasgupta and Prat [2008], we assume that if Investor 3 would deviate and not herd this would imply an off-equilibrium belief of a sincere trade.)

Investment behavior. We now turn to the behavior of investors and take the wage offers as spelt out in Proposition 2 as given. Given a certain realization of their signal, an investor will compare their expected payoff from trading sincerely with their expected payoff from trading against their signal. Denote this payoff difference by $\Delta \pi_{R}$ $=\Delta \pi_{I}+\Delta r$, where $\Delta \pi_{I}$ denotes the expected difference in the profits from trading per se, where $\Delta r$ denotes the expected difference in wages, and where, for ease of exposition, the arguments of the functions are omitted. The respective investor trades sincerely whenever $\Delta \pi_{R}>$ 0 holds (see Equation 3).

Table A1 displays $\Delta r, \Delta \pi_{\mathrm{I}}$, and $\Delta \pi_{R}$ for all information sets of the game. In order to illustrate how the entries of Table A1 are calculated, suppose that investor $i$ has received signal $s^{i}=a$ and faces history $H^{t}$ (recall that investor $i$ buys at time $t=i$ only). In this case, we have

$$
\begin{aligned}
\Delta r= & \operatorname{Pr}\left(v=A \mid a, H^{t}\right) \cdot\left[r\left(v=V^{i}=A\right)-r\left(v \neq V^{i}=B\right)\right] \\
& +\operatorname{Pr}\left(v=B \mid a, H^{t}\right) \cdot\left[r\left(v \neq V^{i}=A\right)-r\left(v=V^{i}=B\right)\right] .
\end{aligned}
$$

For example, suppose it is Investor 3 who has received an $a$-signal and, in addition, both predecessors buy Asset $B$. In this case, Investor 3 would update to an probability of 0.7 of Asset $A$ being the unsuccessful one. Not trading sincerely $\left(V^{i}=B\right)$ would reveal no information about Investor 3's type to the principal (as this would be in line with the candidate equilibrium strategy), and as a consequence Investor 3 receives a wage of 10 . In contrast, if Investor 3 would deviate and purchase asset $A$, the principals would hold an off-equilibrium belief of sincere trading and, depending on the success of the investment, offer a wage of either 12.86 or 3.33. As a consequence, in this case, Equation 6 would imply $\Delta r=3 / 10$ (12.86 -

Table A1. Expected payoff differences from following respectively acting against one's signal in treatment reputation.

\begin{tabular}{lllllc}
\hline Investor & Information Set & $\operatorname{Pr}\left(v=A \mid s^{i}, H^{t=i}\right)$ & $\Delta r$ & $\Delta \pi_{I}$ & $\Delta \pi_{R}$ \\
\hline 1 & $a$ & 0.7 & 3.81 & 4.0 & 7.81 \\
1 & $b$ & 0.3 & 3.81 & 4.0 & 7.81 \\
2 & $A a$ & 0.84 & 6.48 & 3.4 & 10.88 \\
2 & $B b$ & 0.16 & 6.48 & 3.4 & 10.88 \\
2 & $A b$ or $B a$ & 0.5 & 0.0 & 3.4 & 3.4 \\
3 & $A B a$ or $B A a$ & 0.7 & 3.81 & 4.0 & 7.81 \\
3 & $A B b$ or $B A b$ & 0.3 & 3.81 & 4.0 & 7.81 \\
3 & $A A a$ & 0.93 & 8.20 & 2.3 & 10.5 \\
3 & $B B b$ & 0.07 & 8.20 & 2.3 & 10.5 \\
3 & $A A b$ & 0.7 & -3.81 & 2.3 & -1.51 \\
3 & $B B a$ & 0.3 & -3.81 & 2.3 & -1.51 \\
\hline
\end{tabular}


10) $+7 / 10(3.33-10)=-3.81$. At the same time, in the present case, we have $\Delta \pi_{I}=9.3-7.0=2.3$ : while the expected payoff from trading sincerely is zero, when following the herd Investor 3 has to pay a market price of 9.3 for Asset $B$, which according to the information he or she holds has an expected value of 7 only (see Table 1). Hence, $\Delta \pi_{R}=\Delta \pi_{I}+\Delta r=2.3-3.81=-1.51$, and Investor 3 should optimally herd in this case. (As discussed in the section Investors with Reputational Concerns, the asset prices presented to subjects are calculated under the assumption that trade is sincere in both treatments. If, in line with Dasgupta and Prat [2008], the market maker would anticipate herding by Investor 3 and set asset prices accordingly, in the present case one would have $\Delta \pi_{I}=1.4$ and $\Delta \pi_{R}=-2.41$. Hence, the same theoretical prediction would emerge.)

All remaining values of $\Delta r, \Delta \pi_{I}$, and $\Delta \pi_{R}$ are derived in a completely analogous way.

\section{Appendix B}

\section{Experimental instructions: English translation}

As discussed in the section Experimental Design, both rounds of a session had the same basic structure. The instructions for the respective round were handed to subjects and read out aloud by the experimenter. In addition, the main features of the respective round were explained via a flip chart to subjects. Decision sheets for the respective round were only distributed after all subjects had correctly completed a questionnaire about details of the experimental setup. In the second round, investors and observers faced slightly different questions, where the wording was adjusted to take account of the different roles of the participants. The below instructions contain the second-round questionnaire that principals had to complete. Participants were given the opportunity to record their firstround decisions on a separate sheet of paper, to which they had access in the second round of the experiment. Importantly, we made it clear to subjects that secondround decision making did not require recalling firstround decisions. Only after the second round, payments were calculated, subjects answered a postexperimental questionnaire requesting demographic information as well as asking questions about the experiment. Finally, payments were privately handed out to subjects, after which the experiment ended.

All phrases emphasized in the subsequent translation were also emphasized in the original instructions. Square brackets contain explanations intended for the reader and were not part of the original instructions.

\section{Instructions}

\section{Welcome}

Welcome to our experiment. The laboratory for experimental economics-AWI Lab-at the Department of Economics of the University of Heidelberg (game administrator: Professor Roider) aims to test various scientific theories with this experiment.

\section{Payment}

By participating in the experiment, you support our scientific work. You are guaranteed to receive 4 Euros. At the same time, you may earn additional money through your decisions in the experiment.

A more detailed explanation of how your payment is calculated will be provided later. Each point earned in our experiment corresponds to 0.20 Euro. The experiment will take approximately 120 minutes.

\section{The experiment}

The experiment consists of two rounds that are completely independent of each other. In each round the players are randomly assigned to groups (which will change from round to round), and players will have to take investment decisions. To aid you in your decision, you will receive information about the potential success of various investments and you will learn the decisions of your predecessors in your group.

Now, on to the game!

[Start of instructions for Round 1]

\section{Round 1}

\section{The investment decision}

Each group consists of three investors, who sequentially make investment decisions. Each investor must choose between two shares (A and B). Only one share will turn out to be successful and have a value of 10 points at the end. The other share will turn out to be worthless and have a value of 0 points. Which share is successful, is determined randomly before the first investor of the respective group makes his decision. Hence, the same share is successful for all investors in your group. Without additional information you can rely on the fact that in $50 \%$ of cases Share A is successful and in $50 \%$ of cases Share B is successful.

\section{Additional information}

Each investor can observe the investment decisions of his or her predecessors in his or her group.

Moreover, prior to making his decision, every investor receives an additional tip about whether Share A or B is 
successful. The reliability of the tip depends on which of two possible sources of information the investor can draw on: a good source of information or a bad source of information. Which of the two sources of information is available to a given investor is determined randomly, and may differ across investors even within a given group. For each investor, the probability of drawing on a good source of information is the same and equal to $50 \%$. Likewise, for each investor, the probability of drawing on a bad source of information is $50 \%$.

Each investor knows neither the quality of his or her source of information nor the quality of the source of information any other investor is drawing on.

Bad source of information. Investors who "draw on a bad source of information" are privately shown a ball that is randomly drawn from an urn containing 5 "ABalls" and 5 "B-Balls." For each of these investors, a new ball is drawn from this 5:5 urn (where the respective ball is returned to the urn after it has been shown to the respective investor). Consequently, these investors might be receiving different tips.

Good source of information. Investors who "draw on a good source of information" are privately shown a ball that is randomly drawn from an urn where the number of A-Balls and B-Balls in the urn depends on which asset is successful. If Asset $A$ is successful, the urn contains 9 A-Balls and 1 B-Ball. If, however, Asset B is successful, the urn contains $9 \mathrm{~B}$-Balls and $1 \mathrm{~A}$-Ball. For each of the investors who can draw on a good source of information a new ball is drawn from this 9:1 urn (where the respective ball is returned to the urn after it has been shown to the respective investor). Consequently, these investors might be receiving different tips too.

Each investor knows his own tip only and does not observe the tips other investors have received.

Summary. Each investor in your group faces the same problem as you do. He has to choose between Share A and Share B. Each investor receives a tip in form of an A-Ball or a B-Ball, which only he or she can observe. Each investor knows neither the quality of their source of information nor the quality of the source of information any other investor is drawing on. However, prior to making their decision, each investor can observe the decisions of their predecessors in their group (if applicable), and they can observe the prices (and history of prices) of the shares.

\section{Prices}

Each investor who decides on buying a certain share has to pay the current share price. The current price of a given share is adjusted upward or downward on the basis of the observed investment decisions by the experimenter.

Each investor receives an endowment of 20 points for Round 1 of the experiment.

\section{We elicit your decision for every possible scenario}

In the following, we will ask for your decision for every possible scenario that may occur.

In particular, you will be asked to put yourself in the shoes of Investor 1 and to make a decision for the case that you are shown an A-Ball as well as for the case that you are shown a B-Ball. Subsequently, you will be asked to put yourself in the shoes of Investor 2 and to make a decision for every possible combination of Investor 1 's decision and tip that you might receive.

Finally, you will be asked to put yourself in the shoes of Investor 3 and to again make decisions for every possible scenario.

\section{Calculation of your payment}

How do we calculate the payment that you receive at the end of the experiment? Once the experiment has ended and after all investment decisions have been made, for each group the experimenter will randomly determine who occupies the role of Investor 1, Investor 2, and Investor 3. Subsequently, for each group there will be random draws (according to the rules described above) that determine (a) which share is the successful one, (b) from which urn the tip for the respective investor is picked, and (c) the tip that the respective investor is shown.

As an example, suppose that you have been assigned the role of Investor 1, and an A-Ball has been drawn for Investor 1 . In this case, the decision you made for Investor 1 given that he or she is shown an A-Ball would determine your payment.

Now, suppose that you have been assigned the role of Investor 2. Furthermore, suppose that your group's Investor 1 has bought Share B (given the random draws specified above), and an A-Ball has been drawn for Investor 2. In this case, the decision you made for Investor 2 in the scenario (Investor 1 bought B, your tip: ABall) would determine your payment.

Completely analogous, if you have been assigned the role of Investor 3, your payment is determined by the decision you made in the relevant scenario (i.e., given your predecessors' decisions and own tip that are selected according to the rules just described).

Hence, by the above procedure, one of your decisions is selected and determines your payment. The number of points that results from this decision depends on the true value of the share you have bought and the share price you have paid. In any case, the share price you have paid is deducted from your endowment. This will 
be your payment for the current round if your share is not the successful one. If, on the other hand, the share you have bought is successful, you receive 10 additional points. Hence, one of the decisions you have made in this round determines your payment.

The composition of groups will remain anonymous. You will not learn the identity of your fellow investors.

\section{Have you understood everything?}

Before you continue, please answer the following questions so that we can ensure that you have understood everything:

1. Before you observe a ball: What is the probability that Share A is the successful one?

- $50 \%$

- $90 \%$

2. Suppose that you have access to the good source of information. What is the probability that you observe a ball that represents the correct share?

- $50 \%$

- $90 \%$

3. What is the probability that you observe a ball from the good source of information?

- $50 \%$

- $90 \%$

4. What kind of information does Investor 1 receive before he or she makes their decision?

- Their tip in form of a ball and the share prices

- Their tip in form of a ball and the quality of their source of information

- Their tip in form of a ball, the quality of their source of information, and which of the shares has a value of 10

5. What kind of information does Investor 2 receive before he or she makes their decision?

- Their tip in form of a ball, and current and past share prices

- Their tip in form of a ball and the quality of their source of information

- Their tip in form of a ball, current and past share prices, and the decision of Investor 1

- Their tip in form of a ball, the quality of their source of information, and which of the shares has a value of 10

6. What kind of information does Investor 3 receive before he or she makes their decision?

- Their tip in form of a ball, the quality of their source of information, and which of the shares has a value of 10

- Their tip in form of a ball and the quality of their source of information

- Their tip in form of a ball, and current and past share prices
- Their tip in form of a ball, current and past share prices, and the decisions made by Investors 1 and 2

7. Suppose that Investor 1 observes an A-Ball as a tip. What tip will Investor 2 receive?

- Investor 2 will also observe an A-Ball

- A new ball is drawn for Investor 2

8. Suppose that both Investor 1 and Investor 2 receive an A-Ball as a tip. What tip will Investor 3 receive?

- Investor 3 will also observe an A-Ball

- A new ball is drawn for Investor 3

9. Suppose that you have bought Share A and that Share A has a value of 10 points. The purchase price amounts to 7 points. Your endowment is 20 points. What is your payment for this round?

- $10-7=3$

- $20+7-10=17$

- $20+10-7=23$

- $20-7=13$

10. Suppose that you have bought Share A and that Share A has a value of 0 points. The purchase price amounts to 4 points. Your endowment is 20 points. What is your payment for this round?

- $20-4=16$

- $20+10-4=26$

- -4

- $10-4=6$

[Participants have to answer all questions. Answers are checked. Only after all participants answer all questions correctly, the following decision sheets are distributed.]

\section{Scenarios in round 1}

\section{Your task}

Put yourself in Investor 1's shoes. Suppose you receive a certain ball as a tip, and subsequently you have to decide whether to buy Share A or Share B at the indicated price. Bold print indicates the price you have to pay for Share A respectively Share B. Now, for each of the scenarios described below, please state whether you want to buy Share A or Share B:

\begin{tabular}{|c|c|c|c|}
\hline \multicolumn{4}{|c|}{ Scenario 1} \\
\hline Price of Share A & 7,0 & & \\
\hline Price of Share B & 7,0 & & \\
\hline You receive an A-Ball. & I buy: & o Share A & o Share B \\
\hline \multicolumn{4}{|c|}{ Scenario 2} \\
\hline Price of Share A & 7,0 & & \\
\hline Price of Share B & 7,0 & & \\
\hline You receive a B-Ball. & I buy: & o Share A & o Share B \\
\hline
\end{tabular}


Now, put yourself in Investor 2's shoes. Suppose you observe both Investor 1's decision and the movement of share prices. In addition, you receive a certain ball as a tip. Now, for each of the scenarios described below, please state whether you want to buy Share A or Share B at the indicated price (in bold print). That is, the price in bold print is the price you have to pay for Share A respectively Share $\mathrm{B}$. The prices to the left are the prices that your respective predecessors had to pay.

\begin{tabular}{|c|c|c|c|}
\hline \multicolumn{4}{|c|}{ Scenario 1} \\
\hline Investor & 1 & 2 & \\
\hline Price of Share A & 7,0 & 8,4 & \\
\hline Price of Share B & 7,0 & 5,0 & \\
\hline Decision & A & $?$ & \\
\hline You receive an A-Ball. & I buy: & o Share A & o Share B \\
\hline \multicolumn{4}{|c|}{ Scenario 2} \\
\hline Investor & 1 & 2 & \\
\hline Price of Share A & 7,0 & 5,0 & \\
\hline Price of Share B & 7,0 & 8,4 & \\
\hline Decision & B & $?$ & \\
\hline You receive an A-Ball. & I buy: & o Share A & o Share B \\
\hline
\end{tabular}

[The structure of the remaining two scenarios that Investor 2 may face is completely analogous, and therefore these scenarios are omitted from this translation of the experimental instructions.]

Now, put yourself in Investor 3's shoes. Suppose you observe the investment decisions of the first two investors and the movement of share prices. In addition, you receive a certain ball as a tip. Now, for each of the scenarios described below, please state whether you want to buy Share A or Share B at the indicated price (in bold print). That is, the price in bold print is the price you have to pay for Share A respectively Share B. The prices to the left are the prices that your respective predecessors had to pay.

\begin{tabular}{|c|c|c|c|}
\hline \multicolumn{4}{|c|}{ Scenario 1} \\
\hline Investor & 1 & 2 & 3 \\
\hline Price of Share A & 7,0 & 8,4 & 7,0 \\
\hline Price of Share B & 7,0 & 5,0 & 7,0 \\
\hline Decision & A & B & $?$ \\
\hline You receive an A-Ball. & I buy: & o Share A & o Share B \\
\hline \multicolumn{4}{|c|}{ Scenario 2} \\
\hline Investor & 1 & 2 & 3 \\
\hline Price of Share A & 7,0 & 8,4 & 7,0 \\
\hline Price of Share B & 7,0 & 5,0 & 7,0 \\
\hline Decision & A & B & $?$ \\
\hline You receive a B-Ball. & I buy: & o Share A & o Share B \\
\hline
\end{tabular}

[The structure of the remaining six scenarios that Investor 3 may face is completely analogous, and therefore these scenarios are omitted from this translation of the experimental instructions.]
[End of instructions for Round 1 and start of instructions for Round 2]

\section{Round 2}

In Round 2, for investors the rules of the game are the same as in Round 1; only the calculation of the compensation differs, and, in addition to investors, there will now also be observers. If you have just drawn a card with an I, you are still an investor. If you have just drawn a card with a B, you now act as an observer. Thereby, out of all Round 1 investors, we have anonymously and randomly selected 6 participants, who now assume the role of observers.

Observers do not invest, but evaluate the investment decisions made by the investors. The observers are not part of any investor group. The identity of both investors and observers will not be revealed.

Except for how their compensation is calculated, nothing changes for investors.

\section{Calculation of your payment}

This stays the same:

As in Round 1, we will ask for your decision for every possible scenario that may occur.

Again, each investor and each observer receives an endowment of 20 points for Round 2.

After the experiment, i.e., after all investors and observers have made their decisions, the experimenter will again randomly allocate investors to groups. That is, in Round 2 each investor has different group members than in Round 1. Again, the roles of Investor 1, Investor 2, and Investor 3 will be assigned randomly. Again, for each group in Round 2 there will be random draws (according to the rules described above) that determine (a) which share is the successful one, (b) from which urn the tip for the respective investor is picked, and (c) the tip that the respective investor is shown.

Hence, by the above procedure, the decision that determines the payment is selected. That is, as before, one of the decisions an investor makes in this round will determine his or her payment.

This changes:

The true values of the shares continue to affect the investors' compensation. However, the observers' compensation does not depend on the true values of the shares.

The additional compensation that an investor receives depends on the evaluation by the observers. In particular, the observers do no longer decide between the two shares. Instead, observers now have to estimate with which probability an investor had access to a good sources of information when making his or her investment decision, and they will offer wages to individual investors. 
Observers are willing to offer a wage because, by employing an investor with a good source of information, they can earn points. If an observer hires an investor who has access to a good source of information, employing the investor is helpful and the observer receives additional 20 points. An observer does not benefit from hiring an investor with a bad source of information. In this case, the observer receives no additional points.

For each possible scenario and each investor, the 6 observers have to submit wage offers between

0 and a maximum of 20 points (which they would be willing to pay for the respective investor). The observer submitting the highest of the 6 wage offers for a given investor (in a given scenario) hires the respective investor and pays the investor the wage offer he has made. The remaining 5 observers (who did not submit the highest wage offer) do not receive additional points, but also do not have to pay any wage. Now, there are 4 investor groups with a total of 12 investors.

The observers submit their wage offers at a point in time when the true values of the shares can already be observed. On top of that, the observers can only observe the investment decisions of the individual investors and the movement of share prices. They do not observe the tips that investors have received, and they do not observe the qualities of investors' sources of information.

Sequence of events

As in Round 1, after all investors and observers have made their decisions for all possible scenarios, for each group the decisions that determine the compensation and the true values of the shares are determined.

The wage offers of the 6 observers for a given investor in the thus determined setting are compared, and the highest bidding observer wins the respective bid. Thereby, for each investor in each group, both the wage and which observer pays this wage are determined.

It is important to remember that observers do not learn investors' tips and source of information. Observers only observe the investment decisions, the true values of the shares, and the movement of share prices.

The points you will receive are calculated as follows:

\section{Payment to observers}

If an observer has submitted the highest bid for a given investor, he or she pays their bid as a wage to the respective investor. If the respective investor has a good source of information, the observer receives an additional 20 points. If multiple observers submit the same (highest) bid for a particular investor, the winning bidder is determined randomly. Observer who have not submitted the highest bid do not have to pay a wage and do not receive any additional points.

Consequently, a given observer may submit the winning bid for none, one, multiple, or even all 12 of the investor(s). Please note: If an observer would incur an overall loss, he or she will earn 0 points for this round.

Hence, observers' decisions affect both their own as well as investors' compensation.

\section{Payment to investors}

An investor's total compensation is determined by his or her initial endowment, the true value of the share he or she has bought minus the share price he or she has paid, and the wage received from one of the observers.

[The below version of the questionnaire had to be completed by observers. Investors faced slightly different questions, where the wording was adjusted to take account of the different role of the subject.]

\section{Have you understood everything?}

Before you continue, please answer the following questions so that we can ensure that you have understood everything:

1. Suppose that you have submitted a wage offer of 9 points and won the bid. The investor whom you are, hence, employing has bought Share A, and Share A has a true value of 10 points. The investor has an initial endowment of 20 points and has bought Share A for a price of 6 points. Moreover, the investor has a good source of information.

(a) What is the investor's total compensation in the current round?

- $9+10-6+20+20=53$

- $9+20=29$

- $9+10-6+20=33$

(b) What is your payoff from employing this investor (excluding your initial endowment)?

- $20-9=11$

- $20+10+9-6=33$

- $9+20=29$

(c) What would your compensation have been if the investor had had a bad source of information and you had won the bid (excluding your initial endowment)?

- $0-9=-9$

- $20+10+9-6+0=33$

- $9+0=9$

(d) Now, suppose that the share has a true value of 0 points. What is the investor's total compensation?

- $9+0-6+20+20=43$

- $9+20=29$

- $9+0-6+20=23$

2. You and one other observer have bid 14 points for an investor. Who wins? 
- Both of the observers win the bid. The profit is shared equally.

- The winner is selected randomly

- None of the observers wins the bid

3. To what kind of information do you have access when deciding on your wage offer?

- The investors' sources of information and the true values of the shares

- The tips the investors have received and the true values of the shares

- The investors' decisions and the movement of prices

- The investors' decisions, the movement of prices, and the true values of the shares

[Participants have to answer all questions. Answers are checked. Only after all participants answer all questions correctly, decision sheets are distributed. Investors and observers are handed different decision sheets, where each group only observes its own decision sheet.]

\section{Scenarios in round 2 [decision sheet of investors]}

Please note: Round 2 and Round 1 are independent of each other.

[The remainder of the Round 2 decision sheet of investors is identical to the Round 1 decision sheet displayed above, and it is therefore omitted from this translation of the experimental instructions.]

\section{Scenarios in round 2 [decision sheet of observers]}

\section{Your task}

Below, we display all scenarios that may occur. For each scenario, please indicate what wage offer between 0 and 20 you want to make for Investor 1 , Investor 2 , and Investor 3, respectively. In each case, you can observe the movement of prices, the prices each investor faced, which share each investor bought, and which of the shares turned out to be successful.

\begin{tabular}{lcccc}
\hline & \multicolumn{5}{c}{ Scenario 1 } & \\
\hline Investor & 1 & 2 & 3 & \\
Price of Share A & 7,0 & 8,4 & 7,0 & \\
Price of Share B & 7,0 & 5,0 & 7,0 & Successful share: A \\
Decision & A & B & A & .
\end{tabular}

Your wage offer for Investor 1:

Your wage offer for Investor 2:

Your wage offer for Investor 3:

[The structure of Scenarios 2 through 15 that an observer may face is completely analogous, and therefore these scenarios are omitted from this translation of the experimental instructions.]

\begin{tabular}{lcccc}
\hline \multicolumn{5}{c}{ Scenario $\mathbf{1 6}$} \\
\hline Investor & 1 & 2 & 3 & \\
Price of Share A & 7,0 & 5,0 & 3,0 & \\
Price of Share B & 7,0 & 8,4 & 9,3 & Successful share: B \\
Decision & B & B & B & Such
\end{tabular}

Your wage offer for Investor 1:

Your wage offer for Investor 2:

Your wage offer for Investor 3:

[After subjects hand in their Round 2 decision sheets they answer the following postexperimental questionnaire.]

\section{Personal data and questionnaire}

Thank you for participating in the experiment. We will now calculate your total points, convert it into Euros, and then hand you your payment. This may take a few minutes. In the meantime, we would like to ask you to complete the following questionnaire.

Please do not talk to other participants and please refrain from using your cell phone until the end of the experiment.

As soon as we have determined your payoff, we will call your number.

Thank you again for your participation!

\section{Personal data}

Please answer the following questions. Of course, the results of the experiment will be anonymized, and it will not be possible to connect the results to your personal data. The information you share with us will be used for scientific purposes only.

[Data entry fields for age, gender, student status, $\mathrm{PhD}$ status, field of studies, year of studies.]

\section{Questionnaire}

We would like to ask you to answer the following questions.

1. What would you do in the following situation? Suppose you have just won 100,000 Euros in a lottery. Immediately after receiving this money, you are offered the following lottery: There is a chance to double your money, but, at the same time, it is equally possible that you could lose half of the amount you invested.

You can wager your entire 100,000 Euros, a fraction thereof, or you can choose not to take part in this lottery at all.

What fraction of your winnings do you want to wager on this risky, but potentially profitable lottery?

- the entire 100,000 Euros

- 80,000 Euros

- 60,000 Euros 
- 40,000 Euros

- 20,000 Euros

- Nothing, I would not take part in this lottery

2. Do you think that Investor 1 always has decided as suggested by the tip he or she has received?

3. Do you think that Investor 2 always has decided as suggested by the tip he or she has received? If not: When did he or she not act in line with his or her tip?

4. Do you think that Investor 3 always has decided as suggested by the tip he or she has received? If not: When did he or she not act in line with his or her tip?

5. When acting as an investor, did you base your decisions on the tips you received or on the other investors' decisions?

6. What do you think was the purpose of this experiment?

7. In your daily decision making, are you inclined to follow

- other people's advice

- your own assessment

- other people's advice in some situations and my own assessment in others

Thank you for filling out the questionnaire and for taking part in the experiment.

Please wait until your number is called.

\section{Appendix C}

\section{Example for how individual payoffs were calculated in the experiment}

In the following, we provide an example of how subjects' payoffs were calculated in treatment reputation. In each session of treatment reputation, 6 randomly selected subjects acted as principals, while the remaining 12 subjects acted as investors. For the sake of the example, denote the 12 subjects who acted as investors by $S^{j}$ for $j=1$, ...,12. As discussed in the section Experimental Design, after all subjects had handed in their decision sheets, individual payoffs of subjects were calculated in the following way. In a step (i), the 12 investors are randomly allocated into 4 groups of 3 investors each, and the roles of investors 1, 2, and 3 are randomly assigned. Suppose that this random draw leads to one of these groups being comprised of $S^{2}, S^{5}$, and $S^{4}$, who act as investors 1,2 , and 3 , respectively. Furthermore, suppose that (as described in the section Experimental Design) in the random draws of step (ii), it turns out that asset $A$ is the successful one, $S^{2}$ is a good type and receives signal $a, S^{5}$ is a good type and receives signal $b$, and $S^{4}$ is a bad type and receives signal $b$. Then, from the decision sheet of $S^{2}$ (see Appendix B), we look up $S^{2}$ 's decision given that he or she plays Investor 1 and has received signal $a$. Let's say $S^{2}$, s decision is to buy $A$. Subsequently, we turn to $S^{5}$ 's decision sheet (who in the current example acts as Investor 2). There, we look up his or her decision given that Investor 1 has chosen $A$ and $S^{5}$ has received signal $b$. Let's say $S^{5}$ 's decision is to buy $B$. Lastly, we turn to $S^{4}$ 's decision sheet (who in the current example acts as Investor 3). There, we look up his or her decision given that Investor 1 has chosen $A$, Investor 2 has chosen $B$, and $S^{4}$ has received signal $b$. Let's say $S^{4}$ 's decision is to buy $A$. Thereby, we have determined the payoff-relevant decisions of $S^{2}, S^{5}$, and $S^{4}$ (which are given by $A, B$, and $A$, respectively). Moreover, given that in the present example asset $A$ is the successful one, we can now calculate each investor's payoff that he or she obtains from buying the respective asset (where it turns out that $S^{2}$ and $S^{4}$ bought the successful Asset $A$, while $S^{5}$ bought the unsuccessful Asset $B$ ).

To determine the wages of $S^{2}, S^{5}$, and $S^{4}$, we proceed in the following way. In the decision sheets of the six principals we look up the principals' wage offers for Investor 1 , Investor 2 , and Investor 3 given a history of decisions $H^{4} \in\{A B A\}$ and given that $A$ is the successful asset (see Scenario 1 in the decision sheet of principals in Appendix B). $S^{2}$ (who, in the present example, acted as Investor 1) will then receive as a wage the highest offer made for Investor 1 , and the respective highest-bidding principal gets a payoff from employing $S^{2}$ (i.e., 20 minus the wage, because, in the present example, $S^{2}$ is a good type). Likewise, $S^{5}$ (who, in the present example, acted as Investor 2) will then receive as a wage the highest offer made for Investor 2 , and the respective highest-bidding principal gets a payoff from employing $S^{5}$ (i.e., 20 minus the wage, because, in the present example, 20 minus the wage, because, in the present example is a good type). Finally, $S^{4}$ (who, in the present example, acted as Investor 3) will then receive as a wage the highest offer made for Investor 3, and the respective highest-bidding principal gets a payoff from employing $S^{4}$ (i.e., 0 minus the wage, because, in the present example, $S^{4}$ is a bad type). 